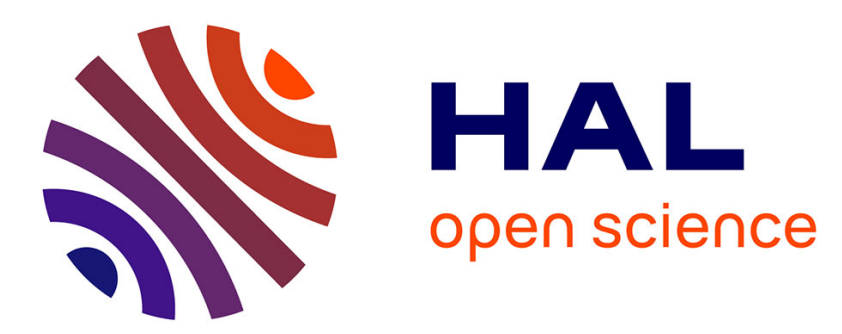

\title{
Modeling water exchange between Baltimore Harbor and Chesapeake Bay using artificial tracers: seasonal variations
}

Bo Hong, Nauth Panday, Jian Shen, Harry V. Wang, Wenping Gong, Anna Soehl

\section{To cite this version:}

Bo Hong, Nauth Panday, Jian Shen, Harry V. Wang, Wenping Gong, et al.. Modeling water exchange between Baltimore Harbor and Chesapeake Bay using artificial tracers: seasonal variations. Marine Environmental Research, 2010, 70 (1), pp.102. 10.1016/j.marenvres.2010.03.010 . hal-00598203

\section{HAL Id: hal-00598203 https://hal.science/hal-00598203}

Submitted on 5 Jun 2011

HAL is a multi-disciplinary open access archive for the deposit and dissemination of scientific research documents, whether they are published or not. The documents may come from teaching and research institutions in France or abroad, or from public or private research centers.
L'archive ouverte pluridisciplinaire HAL, est destinée au dépôt et à la diffusion de documents scientifiques de niveau recherche, publiés ou non, émanant des établissements d'enseignement et de recherche français ou étrangers, des laboratoires publics ou privés. 


\section{Accepted Manuscript}

Title: Modeling water exchange between Baltimore Harbor and Chesapeake Bay using artificial tracers: seasonal variations

Authors: Bo Hong, Nauth Panday, Jian Shen, Harry V. Wang, Wenping Gong, Anna Soehl

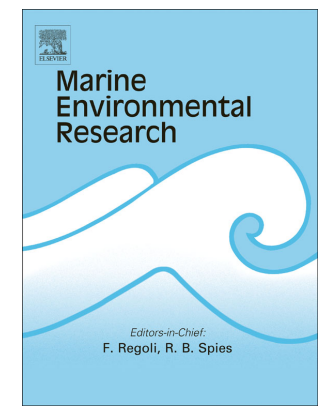

PII: S0141-1136(10)00050-4

DOI: 10.1016/j.marenvres.2010.03.010

Reference: MERE 3437

To appear in: Marine Environmental Research

Received Date: 22 October 2009

Revised Date: 12 March 2010

Accepted Date: 24 March 2010

Please cite this article as: Hong, B., Panday, N., Shen, J., Wang, H.V., Gong, W., Soehl, A. Modeling water exchange between Baltimore Harbor and Chesapeake Bay using artificial tracers: seasonal variations, Marine Environmental Research (2010), doi: 10.1016/j.marenvres.2010.03.010

This is a PDF file of an unedited manuscript that has been accepted for publication. As a service to our customers we are providing this early version of the manuscript. The manuscript will undergo copyediting, typesetting, and review of the resulting proof before it is published in its final form. Please note that during the production process errors may be discovered which could affect the content, and all legal disclaimers that apply to the journal pertain. 
1 Modeling water exchange between Baltimore Harbor and Chesapeake Bay

2 using artificial tracers: seasonal variations

3
Bo Hong $^{1 *}$, Nauth Panday ${ }^{2}$, Jian Shen ${ }^{1}$, Harry V. Wang ${ }^{1}$, Wenping Gong ${ }^{3}$, and Anna Soehl ${ }^{2}$

1. Virginia Institute of Marine Science, College of William and Mary, Gloucester Point, VA 23062, USA

2. Maryland Department of Environmental Quality, Baltimore, MD 21230

3. School of Marine Science, Sun Yat-Sen University, 135West Xingang Rd., Guangzhou 510275, China

To be submitted to Marine Environmental Research

*Corresponding author:

Dr. Bo Hong

Virginia Institute of Marine Science, College of William and Mary

Rt. 1208, Greate Road, P. O. Box 1346

Gloucester Point, VA 23062, USA

Phone: 804-684-7897

Fax: 804-684-7899

Email: andyhong@vims.edu 
1 Abstract Understanding the dynamics of water exchange between Baltimore Harbor and the

2 Chesapeake Bay is essential when evaluating transport and fate of dissolved substances in both of these systems. Conservative artificial tracers are used in this study to investigate transport processes through a three-dimensional hydrodynamic model (CH3D). The model well reproduced the three-layered circulation pattern in Baltimore Harbor. Several numerical experiments are performed to trace the water mass coming from different sources. The results indicate that both the upper and lower layers of the Harbor are the dominant pathways of transporting dissolved substances from Susquehanna River to the Harbor. Such inward transport is intensified (suppressed) during the high-discharge (low-discharge) period. The upper layer inflow transports water mass with high concentrations of dissolved substances while the inflow from the lower layer transports water mass with low concentrations of dissolved substances. The bottom layer is the dominant pathway for transporting dissolved substances from the lower Bay to the Harbor. Lower river discharge and stronger along-Bay pressure gradient (resulting in stronger landward residual flow in the bottom layer of the Bay) facilitate the bottom intrusion of dissolved substances from lower Bay to the Harbor. Once contaminants are transported into the Harbor, they usually stay for a longer time in the mid-depth of the Harbor than those in other layers due to the threelayer circulation in the Harbor. The time needed for the contaminants being transported out of the Harbor during a typical low-discharge period is about 1 month longer than that needed during a typical highdischarge period. The results, from the environmental perspective, provide new insights for quantitative evaluation on the transport processes of the dissolved biogeochemical substances between Baltimore Harbor and Chesapeake Bay.

Keywords: Water exchange; three-dimensional model; Tracer; Age; Baltimore Harbor; Chesapeake Bay (1)

(1)

(5)

6

28 


\section{Introduction}

Baltimore Harbor is a tributary embayment in the upper western portion of Chesapeake Bay draining a highly urbanized and industrialized Patapsco River basin (Fig. 1). Water quality and ecosystem health in the Harbor is susceptible to the industrial, municipal, and stormwater runoff from the surrounding watershed as well as the inflow from the adjacent Bay. Excessive nutrient runoff from the Chesapeake Bay drainage basin is known to contribute to the hypoxia or anoxia events in deepwater (referred to as "dead zone") in the mainstem of the Bay during much of the summer (Kemp et al., 2005). These deepwater are not only harmful to the aquatic life in the Bay itself, but can also spread into most of the nearby embayments (Kuo and Neilson, 1987). Owing to the different source and transport pathways of dissolved substances, the quantitative interpretation of water exchange between Baltimore Harbor and the Bay is necessary for better protecting and utilizing the environmental resources in these areas.

The stratification in upper Chesapeake Bay is maintained by dynamic processes associated with freshwater discharged into the system primarily by the Susquehanna River, resulting in a two-layered circulation (Schubel and Pritchard, 1986). Baltimore Harbor has relatively small drainage areas. The combined average daily discharge of the tributaries to the Harbor represents only about 1/315 of the volume of the Harbor (Schubel and Pritchard, 1986). The mean tidal range of the Harbor is about $0.35 \mathrm{~m}$ and the tidal currents in the Harbor are relatively weak (http://tidesandcurrents.noaa.gov). The estimated maximum tidal excursion is about $2.63 \mathrm{~km}$. Given the insignificant freshwater discharge and the low tidal energy input to the Harbor, the unique three-layered circulation developed in the Harbor and the stratification are mainly controlled by the density conditions in the adjacent Bay.

Although the three-layered circulation in Baltimore Harbor has been extensively investigated by many previous studies (e.g., Carpenter, 1960; Stroup et al., 1961; Cameron and Pritchard, 1963; Chao et al., 1996), quantitative evaluation of the water exchange and pollutant transport processes between the Harbor and the Bay from the environmental prospective is still very limited. The questions that need to be further addressed include: (i) what amount of dissolved pollutants in the Baltimore Harbor is associated with the inflow from the main Bay? (ii) how long does it take for these substances to be transported from the source area to the area of 
1

2

concern? and (iii) how does the transport time-scale change spatially and temporally under different hydrodynamic conditions?

Transport of water and dissolved substances in estuary is strongly influenced by numerous factors such as river discharge, tides, wind, bottom topography, Coriolis effect, etc. It is usually difficult to trace water mass ( or nutrients, dissolved pollutants, etc. ) coming from different source regions in in-situ observations since hydrodynamic processes usually result in the mixture of them. However, the fate and transport timescales of these biogeochemical substances are essential to both oceanographic research and environmental assessment. Using artificial tracers in numerical modeling is one of the feasible methods that can be used to address the problem.

Previous studies have demonstrated the advantages of using artificial tracers in numerical simulations to determine the fate and transport timescales of dissolved substances since they left the source region. For example, Hirst (1999) examined the penetration and fate of North Atlantic Deep Water in a global ocean model; Delhez and Deleersnijder (2002) simulated the advectiondispersion of tracers discharged at the nuclear fuel reprocessing plant of Cap de La Hague; Shen and Haas (2004) used a three-dimensional numerical model to calculate the age distribution for the substance released from the head waters of the York River estuary under different hydrodynamic conditions. In addition, both particle trajectories and passive tracers were used in a three-dimensional circulation model by Döös and Engqvist (2007) to estimate the potential fate and distribution of radio-nuclides released in the coastal region of the Baltic Sea. Through age tracer modeling, Gustafsson and Bendtsen (2007) quantified the timescales of downward (upward) mixing of surface (bottom) water in a shallow fjord. In these studies, artificial tracers are integrated simultaneously with the hydrodynamic fields and provide powerful tools that can help us to quantify the transport processes of dissolved substances and understand the mechanisms that control their temporal and spatial variations.

For the purpose of quantifying water exchange between Baltimore Harbor and the mainstem of the Chesapeake Bay, we add conservative artificial tracers in an extensively calibrated threedimensional hydrodynamic model. The hydrodynamic model and the method of quantifying water exchange are introduced in Section 2. Section 3 simply describes the hydrodynamic background of the concerned area. The diagnostic and quantitative analyses of water exchange between Baltimore Harbor and main Bay are presented in Section 4. Discussion and conclusions are provided in Section 5. 


\section{Model Description}

\subsection{Hydrodynamic Model}

A three-dimensional numerical hydrodynamic model (Curvilinear Hydrodynamics in Three Dimensions, CH3D) was used in this study. CH3D was originally developed by Sheng (1986), and subsequently modified extensively by the US Waterways Experiment Station for application to Chesapeake Bay (Johnson et al., 1991; 1993; 1995; Wang and Chapman, 1995). The detailed description and theoretical aspects of CH3D can be found in Johnson et al. (1991). Second order k- $\varepsilon$ turbulence closure model (Kundu, 1980) is used to calculate the eddy viscosity and diffusivity coefficient. The background horizontal diffusivity is set to $1 \times 10^{-5} \mathrm{~m}^{2} \mathrm{~s}^{-1}$. A particular feature of $\mathrm{CH} 3 \mathrm{D}$ is the solution of transformed equations on a boundary-fitted curvilinear coordinates in the horizontal plane. This allows the model grid to cope with the complicated shoreline configuration and keep a good representation of the deep channel orientation in the Chesapeake Bay and its tributaries, whereas high-resolution grids are required in other models with orthogonal curvilinear coordinates to meet the needs of keeping reasonable orthogonalization and good representation of complex estuarine bathymetry.

$\mathrm{CH} 3 \mathrm{D}$ has been successfully used to investigate the hydrodynamic features and transport processes of dissolved substances in the Chesapeake Bay (e.g., Hood et al., 1999; Xu et al., 2002; Shen and Wang, 2007). It is also extended to include the sediment transport (Lin et al., 2004; Park et al., 2008) and biogeochemical sub-model (Xu and Hood, 2006), in which the physical model provides hydrodynamic background for the sediment and biogeochemical constituents in three dimensions. The model grid of this application (developed by Wang et al., 2004) is shown in Fig. 2. There are 19 layers in the vertical with a uniform layer thickness of $1.52 \mathrm{~m}$, except for the top layer whose thickness fluctuates with water level. The model is initialized by the Chesapeake Bay Program (CBP) Monitoring data (http://www.chesapeakebay.net/dataandtools.aspx/). Daily fresh water inflow (http://waterdata.usgs.gov/nwis/dv/) with zero salinity and time-varying temperature was prescribed for the major tributaries, which include Susquehanna River, C\&D Canal, Chester River, Choptank River, and Patapsco River (see Fig. 1 for the locations of these tributaries). At the southern open boundary the tidal elevations are prescribed by hourly data observed at 
Solomons Island, MD (http://tidesandcurrents.noaa.gov/, Station ID: 8577330). The upstream schemes are adopted for the temperature and salinity fields at the southern open boundary condition in which the observed vertical salinity and temperature profiles at Station CB4.4 (see Fig. 2 for its location) are advected into the model domain for the inflow conditions. Since the observed salinity and temperature data are collected at approximately monthly intervals, the data were first linearly interpolated into daily intervals to obtain the annual cycle. Then the station data were interpolated onto the model grid as open boundary forcings. The radiation boundary condition was used for the velocity field. The velocity at the open boundary was calculated in the model based on the observed surface elevation field and the density profile. The daily averaged surface heat exchange and equilibrium temperature are computed from the corresponding meteorological data (NOAA, 2007).

Lin et al. (2004) used this model configuration to simulate hydrodynamic fields covering both very wet and very dry hydrological years. Modeled bottom velocity fields were compared with observations at a mooring station inside the Baltimore Harbor in spring of 2000. The simulated along-Harbor velocity agrees very well with the observations. Park et al. (2008) also used this model configuration to simulate the hydrodynamic field in 1996. By using the two surveys in October followed a peak discharge of $5,267 \mathrm{~m}^{3} \mathrm{~s}^{-1}$ on October 21 and the two surveys in July under the low discharge conditions (data presented in Sanford et al. (2001)), the model performance were validated over a wide range of freshwater discharge values. The spatial distribution characteristics of observed along-Bay salinity profiles were reproduced well by the model. The model-data comparisons at a mooring station indicated that the model could catch the observed vertical structure variations and the vertical mixing scheme worked properly. These model-data comparisons indicated the success of model performance on tidal timescales. Liu et al. (2009) presented a good example of model-data comparisons. They evaluated model skill not only for tidal properties but also for subtidal properties. Since we are focusing on the seasonal variations in this study, further model validation has been conducted to confirm the model performance in modeling seasonal estuarine circulation. Whereas simulations were conducted for multiple years, only the results in 2000 are presented here (similar model performances were obtained in other years). Comparisons between the modeled salinity and CBP monitoring data are shown in Fig. 3a. Model results show consistent seasonal variations with the observations. It is shown that the model can catch the seasonal salinity variations in the upper Chesapeake Bay. 
1 Fig. 3b presents the comparisons of water surface elevation at NOAA observation stations. Both the modeled and observed results are 15-day low-pass filtered before plotting. It can be seen that model results reproduced the seasonal water surface elevations very well. The correlation coefficients (CC) at each station are also presented in Fig. 3b, which are at the 95\% confidence level. The CC at Tolchester is the lowest $(=0.93)$. It can be seen that this model reproduces the upper Bay seasonal variations very well. The present model configuration is robust and suitable for this study.

\subsection{Methods}

Water coming from a specific origin is identified by the passive tracer, which also represents the dissolved substances (contaminants, etc.) in the water. There are two aspects that need to be addressed for quantifying the exchange of water coming from different origins. One is the amount of the dissolved substances, which is represented by the tracer concentration. The other is the transport timescale of the dissolved substances, which is represented by the tracer age (the tracer age is defined as the time elapsed since the tracer under consideration is released into the water body where its age is prescribed to be zero (Delhez et al., 1999)). The concentration and the age of the tracer are calculated in the numerical model using transport equations (Deleersnijder et al., 2001). The tracer concentration equation is

$$
\frac{\partial c(t, \vec{x})}{\partial t}+\nabla \square(\vec{v} c(t, \vec{x})-K \square \nabla c(t, \vec{x}))=0
$$

Where $c(t, \vec{x})$ is the tracer concentration, $\vec{v}$ is the velocity vector, $K$ is the diffusivity tensor, $t$ is the time, and $\vec{x}$ is the spatial coordinate. There is no sink of the tracer within the study area. According to Deleersnijder et al. (2001), the evolution of age concentration $(\alpha(t, \vec{x}))$ is described as

$$
\frac{\partial \alpha(t, \vec{x})}{\partial t}+\nabla \llbracket(\vec{v} \alpha(t, \vec{x})-K \square \nabla \alpha(t, \vec{x}))=c(t, \vec{x})
$$

Then the mean age $(a(t, \vec{x}))$ can be calculated as

$$
a(t, \vec{x})=\frac{\alpha(t, \vec{x})}{c(t, \vec{x})}
$$

At the releasing site, the tracer concentration is 1 (arbitrary unit) and the tracer age is zero. The tracer age at any other location is representative of the timescale for water or a dissolved 
substance to be transported from its source to this location. The spatial and temporal variations of tracer concentration and mean age (hereafter referred to "water age") will be used in the following to quantify the water exchange under different hydrodynamic conditions.

\subsection{Numerical Experiments Design}

In this study, tracers are released from three different locations in three independent experiments for quantifying water exchange between the Baltimore Harbor and Chesapeake Bay. Previous studies have indicated that the circulation in the upper Chesapeake Bay is driven primarily by the discharge of Susquehanna River (Schubel and Pritchard 1986). In order to obtain more general results of seasonal variation, we use the climatological daily river runoff data (1985-2007) instead of using the data from a single year. In reality, the perturbation/mixing induced by wind forcing is more complicated (MacCready et al., 2009). We exclude the wind effect in this study for simplicity and only focus on the effects of river discharge, which is the dominant physical process determining the seasonal variation in the upper Bay. We are aware of the importance of wind mixing as it affects the estuarine stratification. Wind effects are more dominant during synoptic events. The influences of short-term wind events on long-term stratification and long-term transport warrant more observations and studies and will be studied separately. The three tracer simulation experiments are hereafter referred to as Exp. 1, Exp. 2, and Exp. 3. In Exp. 1, tracers are continuously released from the entrance of Susquehanna River, which are used to track the water masses (contaminants, etc.) coming from Susquehanna River. In Exp. 2, tracers are continuously released from the mid-Bay (along the southern open boundary of the model), which are used to track the water masses coming from the lower Bay. In Exp. 3, tracers are instantaneously released over the entire Baltimore Harbor, which are used to track the dissolved substances over the Harbor. There is no other source of tracer in each experiment. Hydrodynamic equations and passive tracer equations are integrated simultaneously. In order to reach the dynamic equilibrium condition and eliminate transition errors resulting from model spin-up, the model is run repeatedly for 2 years with the annual cycle forcing fields. Only outputs of the last year are used for the following analyses. Note that the spin-up time in Chesapeake Bay is relatively longer than most estuaries, for example, the spin-up time is less than two weeks for Columbia River estuary hindcast modeling (Liu et al., 2009). This is due to the relatively slow adjustment of baroclinic fields in the highly stratified Chesapeake Bay. 


\section{Circulation patterns}

To understand the long-term variability of water exchange between the Harbor and the Bay, two fundamental processes need to be addressed. The first one is the variation of the Susquehanna River discharge. Susquehanna River has a seasonal flow pattern typical of midlatitude rivers: high discharge in spring produced by snow melting and spring rains followed by low-to-moderate flow throughout most of the remainder of the year (Carpenter, 1960; Schubel and Pritchard, 1986). This variation greatly impacts the vertical stratification of the main Bay, horizontal salinity gradients between the Bay and Baltimore Harbor, and the amount of dissolved substances transported by river discharge. The second one is the impact of deep water coming from lower Chesapeake Bay, in which the high-salinity water is advected up-Bay mainly through non-tidal gravitational circulation (Pritchard, 1956). Because of the persistence of stratification and strong two-layered circulation developed in the main Bay, the flow in the bottom layer not only plays a role of conveying saline water from the lower Bay to the upper Bay, but also conveys biogeochemical substances that mix into the deep water during various destratification events.

The Susquehanna River discharge accounts for $87 \%$ of the total river runoff in the upper Chesapeake Bay. The 23-year (1985-2007) daily mean river runoff of Susquehanna River (Fig. 4) indicates that the maximum (minimum) river discharge usually appears in March-April (JulyOctober), which can be defined as the typical high-discharge (low-discharge) period. Baltimore Harbor is famous on its three-layered circulation pattern driven by differences in the vertical salinity structure in the Harbor and in the adjacent Chesapeake Bay (Carpenter, 1960; Stroup et al., 1961; Boicourt and Olson, 1982; Chao et al., 1996). The typical three-layered circulation in Baltimore Harbor is shown in Fig. 5a (after Cameron and Pritchard, 1963). The characteristic salinity distribution of the Harbor has the conventional positive seaward gradient in the lower layer, but a negative seaward gradient nearer the surface. Thus, there is flow into the Harbor both at the surface and at the bottom driven by the pressure gradient. These inflows return to the Chesapeake Bay at mid-depth. Figs. $5 b$ and $5 c$ present the typical three-layered circulation (along the navigation channel of the Harbor, transect I in Fig. 2) simulated in this study. The model results show similar pattern with that demonstrated by Cameron and Pritchard (1963): in 
the upper water column, the less saline, less dense surface waters of the Bay tend to overflow the more saline, denser surface waters in the Harbor. Near the bottom, the more saline, denser waters of the Bay tend to flow under the less saline, less dense waters of the Harbor. The mid-depth water flows outward to offset the inward flow.

The mean salinity of Chesapeake Bay is a product of two competing processes, i.e., freshwater influx into the Bay through rivers and exchange with the adjacent ocean (Austin, 2002). The modeled surface salinity fields in the upper Chesapeake Bay averaged during the typical highdischarge and low-discharge periods are shown in Fig. 6a. Competitions between the river runoff and lower Bay saline water intrusion are clearly reflected. During the high-discharge period, water in the upper Bay is greatly diluted. The intrusion of the freshet into Baltimore Harbor can be clearly discerned from the isohalines. During the low-discharge period, the saline water takes over much of the domain gradually and the surface fresher water intrusion from the main Bay to the Harbor is greatly weakened and mainly confined to the area along the northern bank of the Harbor. The residual velocity profile across the mouth of Baltimore Harbor (facing west, transect II in Fig. 2) is presented in Fig. 6b. Without the wind forcing, three-layered circulation appears throughout the year, but both the spatial distribution and the strength of the flow vary with time. Uniform surface inward flow usually occurs during the high-discharge period, whereas surface inward flow only occurs near the northern bank of the Harbor during the low-discharge period resulting in the two-layered circulation near the southern bank. The mid-depth outward flow is strengthened when the surface inflow is fully developed during the high-discharge period, and then weakened during the low-discharge period. The inward flow in the bottom layer shows less variation compared with those in the upper layers. This is consistent with the findings of Chao et al. (1996) that indicated the existence of persistent and dominant intrusion into the bottom of the Harbor against all adversities.

\section{Results}

The introduction of artificial tracers in a numerical model is a convenient way to quantify the timescale for the transport process of dissolved substances relative to its source region. It also can reveal the spatial distribution of tracer concentrations of dissolved substances coming from a 
specific source. These are usually difficult to measure in observations. Water exchange between Baltimore Harbor and Chesapeake Bay are investigated below from three different aspects.

\subsection{Water Mass Coming from Susquehanna River (Exp. 1)}

Exp. 1 tracks the dissolved substances coming from Susquehanna River. The selected snapshots (daily mean results sampled at Day 91 and Day 255, respectively) of surface water age distribution are shown in Figs. 7a and $7 \mathrm{~b}$, which correspond to the very high-discharge and very low-discharge conditions (see Fig. 4), respectively. The water age at Day 91 is much lower than that at Day 255, indicating that the transport time of the water mass coming from Susquehanna River during a high-discharge period is much less than that during a low-discharge period. The water age difference between Days 91 and 255 is approximately 70 (40) days at the mouth (head) of the Harbor. The corresponding surface velocity field (Figs. 7e and 7f) shows that the flow at Day 91 is much stronger than that at Day 255. There is strong and consistent surface inflow in the Harbor at Day 91, whereas weak and divergent flow appears in the Harbor at Day 255. These demonstrate that Susquehanna River discharge has substantial influence on water exchange between the Harbor and the main Bay.

Fig. 8 presents the monthly mean water age profiles along the navigation channel in Baltimore Harbor. Since the tracers are continuously released at the entrance of Susquehanna River, the age distribution in Fig. 8 represents the transport timescale needed for the dissolved substances to reach the Harbor. The common feature of the age distribution is that the water age at either the surface or bottom layer of the Harbor is usually lower than that in the mid-depth of the water column. The largest vertical age difference can be about 50 days and appears in winter. After the high-discharge period starts, such vertical difference decreases to about 20 days. The lowest water age appears in April when Susquehanna River is at its maximum discharge. The age starts to increase from May and reaches its maximum in November.

More detailed structure of the water exchange process can be observed from the time evolution of tracer concentration and water age at selected stations (Fig. 9). Stations C, D, and E are located in the mouth, the exterior, and the interior of the Harbor respectively, and Station B is in the main channel of the Bay (see Fig. 2 for these locations). For the water mass coming from the Susquehanna River, the tracer concentration decreases with depth in the Harbor (Figs. 9a-c). The highest tracer concentration $(>80 \%$ at the mouth of the Harbor, $>60 \%$ in the interior of the 
1

Harbor) appears in April. The time required for the tracer concentration in the lower layer to reach its maximum value ( $>30 \%$ ) is delayed approximately a half-month compared with that in the surface layer. When examining the tracer concentration in the main channel of the Bay (Station B, Fig. 9d), we can find such temporal and spatial variations of tracer concentration also occur in the main Bay. The corresponding water age at each station in the Harbor (Figs. 9e-g) show significant temporal variations. In general, the water age during the high-discharge period is about 2 months longer than that during the low-discharge period. As the inflow is greatly weakened during the low-discharge period (Fig. 6 and Fig. 7f), the bottom layer water age in the inner Harbor is aproximately 1 month larger than that at the surface layer due to reduced gravitation circulation. The largest water age appears at about $6 \mathrm{~m}(4 \mathrm{~m})$ depth during the highdischarge (low-discharge) period, corresponding to where the mid-depth outflow exists. Such pattern disappears in the main channel of the Bay (Station B, Fig. 9h) where the water age always increases with depth due to the stratification effect (Shen and Lin, 2006).

4.2 Water Mass Coming from Lower Chesapeake Bay (Exp. 2)

Exp. 2 tracks the water mass coming from the lower Chesapeake Bay. Since the transport timescale of water mass coming from the lower Bay highly relies on the releasing site, the mean age can be different for tracers released at different sites. However, using the same reference site, the results in Exp. 2 are still efficient for studying the variations of transport timescale for dissolved substances coming from the lower Bay. The selected snapshots (daily mean results sampled at Day 91 and Day 255, respectively) of surface age distribution are shown in Figs. 7c and $7 \mathrm{~d}$, which correspond to the very high-discharge and very low-discharge conditions, respectively. A notable feature existing in these two snapshots is that the water age near the head of the Harbor is lower than that in the inner Harbor. Such difference tends to be augmented at Day 255 compared with that at Day 91. In general, the water age near the northern bank of the Harbor is lower than that near the southern bank. Since the water mass coming from the lower Bay mainly occupies the lower layer of the Bay body and enters Baltimore Harbor mainly through the bottom inflow, the detailed vertical structure needs to be examined to reveal the water exchange processes of the lower Bay and the Harbor.

The monthly mean water age profiles along the navigation channel in Baltimore Harbor are shown in Fig. 10. Unlike the results in Exp.1, the highest water age does not manifest in the middepth of the Harbor in Exp. 2, except near the Harbor mouth. The water age decreases 
consistently with depth. The contours are quite flat at the mid-depth. The water age near the bottom of the Harbor is usually less than that near the surface by 40-50 days. During the highdischarge period, bottom water age increases by approximately 20 days. This indicates that the bottom water exchange between the Harbor and the Bay is faster during the low-discharge period than during the high-discharge period.

Fig. 11 presents the depth-time profiles of tracer concentration and water age at selected stations. Tracer concentrations in the Harbor (Figs.11a-c) increase with depth throughout the year. The lowest tracer concentration appears during the high-discharge period (at both the upper and the lower layers of the water column), and then increases gradually as the low-discharge period begins. The tracer concentration during the low-discharge period is usually higher than that during the high-discharge period by $20-30 \%$, and the vertical difference of tracer concentration during the high-discharge period is higher than that during the low-discharge period. Similar patterns can be seen in the main Bay (Fig. 11d). The time evolutions of vertical age profiles at selected stations are shown in Figs. 11e-h. The highest vertical age variations appear at around $6 \mathrm{~m}$, where the haloclines fluctuate with the dynamics. The bottom layer water age is almost the same between the Harbor and the Bay. But in the upper layer, the water age in the Harbor is about 30 days larger than that in the main Bay.

\subsection{Influence of Water Mass in Baltimore Harbor to the upper Bay (Exp. 3)}

The highly urbanized and industrialized watershed draining to the Harbor contributes various contaminants. In order to better understand the potential impact of the Baltimore Harbor watershed on downstream water quality, tracers were released instantaneously in the Harbor (Exp.3). The spatial and temporal variations of these tracers were used to quantify the influences of the contaminants in the Harbor to the Bay. At each grid cell in the Harbor, the tracers were released over the entire water column. Two model runs were conducted under the typical highdischarge and low-discharge conditions, respectively. For the high-discharge simulation, a flow rate of $1900 \mathrm{~m}^{3} \mathrm{~s}^{-1}$ from the Susquehanna River was specified. For the low-discharge simulation, this flow rate specification was $360 \mathrm{~m}^{3} \mathrm{~s}^{-1}$. The temporal evolution of the total tracer concentration for the entire Harbor is shown in Fig. 12. Following the instantaneous release, the total tracer concentration decreases quickly. The decrease of total tracer concentration under the high-flow condition is much faster than that under the low-flow condition, which indicates the 
high-flow condition facilitates the renewal of water in the Harbor. According to Prandle (1984), the turnover time is defined as the time needed for the total mass of a material within the area of interest to be reduced to a factor of $\mathrm{e}^{-1}$, i.e.

$$
R(\tau)=R_{0} e^{-\tau / \tau_{t}}
$$

where $R$ is the total tracer concentration and $\tau_{t}$ is the turn over time. So the total tracer concentration will be reduced by a factor of $\mathrm{e}^{-1}$ at the time $\tau=\tau_{t}$. The turnover time equals the residence time if the concentration in an embayment decrease exponentially (Zimmerman, 1976). The turnover time of the Harbor is 21.7 days (39.5 days) under the high-discharge (lowdischarge) condition. Fig. 13 shows the evolution of tracer concentration in the Harbor under the typical high-discharge condition (a similar pattern develops under the low-discharge condition). It can be shown that dissolved substances in the Harbor usually remain for a longer time in the mid-depth of the Harbor (and upper layer of the inner Harbor) than those in other areas. Thus when organic contaminants are discharged into the Harbor from the drainage basin, the middepth of the Harbor (and the upper layer of the inner Harbor) usually sustains water quality stress over a longer period than other areas.

Examining the conditions at Stations $\mathrm{f}, \mathrm{g}$, and $\mathrm{h}$ can provide additional insight about the influence of Baltimore Harbor outflow on water quality in the main Bay. Stations $\mathrm{f}$ and $\mathrm{h}$ lie in the south and north of the Harbor, respectively, while Station g lies near the mouth of the Harbor (see Fig. 2). These stations are used to represent different areas in the Bay. The depth-averaged tracer concentrations at each station are shown in Figs. 14a and 14b. Under the high-flow condition, the tracer concentrations at Station $g$ are zero at the beginning and start to increase after the first week. The peak tracer concentration appears at around Day 27, at which point it starts to decrease gradually with small perturbations. Similar temporal variations can be observed at other stations, with peaks occurring at different times at each station (Day 35 and Day 45 for Stations $\mathrm{f}$ and $\mathrm{h}$, respectively). The concentration distribution shows the age density function. The calculated mean age values suggest that contaminants in Baltimore Harbor can be transported to the selected stations $\mathrm{f}, \mathrm{g}$, and $\mathrm{h}$ at around 66, 58, and 73 days, respectively, after being released in the Harbor. The mean age under the low-flow condition is about 1 month longer than that under the high-flow condition (around 97, 82, and 105 days for Station f, g, and $\mathrm{h}$, respectively). The appearance of peak tracer concentration under the low-flow condition is 
1

also later than that under the high-flow condition. The time evolution of the vertical tracer concentration profile helps to reveal the distribution of tracer concentration for the entire water column at each station. As an example, the results under the low-flow condition (a similar pattern appears in the high-flow condition) are shown in Fig. 14c. These results suggest that, after the dissolved substances are transported out of the Harbor, they show different vertical occupation patterns in different areas of the main Bay. At the station south (north) of the Harbor, the tracer concentration decreases (increases) with depth. For the station close to the mouth of the Harbor, the highest tracer concentration occurs at around $6 \mathrm{~m}$ depth. The difference in the vertical distribution of tracer concentration at different locations suggests that the contaminants in the Harbor may influence different habitats in the mainstem of the Bay.

\section{Discussion}

The results presented in the previous section (summarized in Table 1) reveal that tracers coming from different origins have different pathways and different transport timescales under the three-layered circulation condition in the Baltimore Harbor. These reflect the difference of water exchange processes with respect to different source origins.

\subsection{Dominant Pathway of Water Exchange for Different Water Sources}

The dissolved substances that originate from Susquehanna River (lower Bay) mainly occupy the upper (lower) layer of the water column both in the upper Bay and in the Harbor and their concentrations decrease (increase) consistently with depth (Figs. 9 and 11). However, this kind of symmetric distribution does not appear in the vertical age distribution. In the case of releasing tracers from the Susquehanna River (Exp. 1), the water age profile along the navigation channel of the Harbor shows a 'sandwich' structure (high water age in the mid-depth and low water age in both the upper and the lower layers, Fig. 8). For the case of releasing tracers from the lower Bay (Exp. 2), the water age within the Harbor shows a monotonic vertical structure (decreasing consistently with depth, Fig. 10). The results in Exp. 1 indicate that both the upper and the lower layer inflow of the Harbor are the dominant pathways of transporting dissolved substances from Susquehanna River to the Harbor. The upper layer inflow, associated with the high concentration of dissolved substances, dominates the mass transport during a typical high-discharge period. But 
1

the mass transportation through the bottom inflow becomes dominant during a typical lowdischarge period. Although the concentrations of dissolved substances associated with the bottom inflow is less than those in the surface inflow, the transportation by bottom inflow is faster than that by the surface inflow during a typical low-discharge period. In Exp. 2, on the other hand, only the inflow from the lower layer is the dominant pathway for transporting dissolved substances from the lower Bay into the Harbor. Because of the persistence of stratification in the main Bay, which prevents the vertical mixing of bottom water to the surface, the transport of water that originates from the lower Bay through the upper layer is still much slower than that in the lower layer, even during a typical high-discharge period with strong surface inflow to the Harbor.

\subsection{Comparison with theoretical scales}

Examining the age distribution for Exp. 2 (Fig. 11), the low age distribution near the bottom does not follow the freshwater discharge, which can be attributed to the influence of the lower Bay through the gravitational circulation. The observed salinity values at Station CB4.4 (see Fig. 2 for its location) is presented in Fig. 15a, which were used as the model open boundary conditions in this study. The temporal vertical salinity distribution shows that there are several high-salinity water intrusion events (i.e., salinity $>20 \mathrm{ppt}$ ) in the bottom layer of the Bay. The depth-time profiles of water age in Exp. 2 are shown in Figs. 15b and 15c, which are sampled at Stations B and C, respectively. It can be seen that the low water age events (and the high tracer concentration events, (Fig. 11)) are usually associated with the high-salinity water intrusion events. Although Station CB4.4 is miles away from Stations B and C, the bottom layer salinity at Stations B and C (figures not shown) have consistent temporal variations with salinity at Station CB4.4. In order to further examine the underlying transport mechanisms, the depth-time profile of modeled along-Bay velocity at Station V (see Fig. 2) is presented in Fig. 15d. A 15-day lowpass filter was applied to the velocity data before the plotting. Thees results clearly show the two-layered gravitational circulation development in the Bay and the bottom residual flow variations are highly in phase with the bottom salinity field. Velocity profiles at other stations in the main channel of the Bay show similar temporal variations to those at Station V. Those results indicate that the higher bottom salinity field usually corresponds to the stronger landward flow resulting in a decrease of water age in the bottom layer (Figs. 15b-c). The gravitational 
1

circulation is critical in changing the transport processes. When the return flow is stronger, tracer transportation is faster, which results in smaller water age. In general, the water age near the bottom of the main Bay decreases about 20 days when the landward residual velocity increases by about $8 \mathrm{~cm} \mathrm{~s}^{-1}$ (Fig. 15).

The gravitational circulation in the estuary is influenced by the combined effect of river discharge and bottom saline water intrusion from the ocean. The competition between freshwater inflow from the head and high-salinity water intrusion from the mouth results in the variation of the along-Bay pressure gradient. The Hansen and Rattray (1965) solution (HR65 hereafter) for the along-channel velocity provides a classical way to quantify the contribution of along-channel pressure gradient and river discharge to the gravitational circulation. Progress has been made since HR65 and several assumptions in HR65 have been relaxed now (e.g., Geyer et al., 2000; MacCready, 2004; 2007). MacCready and Geyer (2010) provide an excellent review on the recent advances of the theoretical solution and formulae for calculating adjustment timescales under perturbations. Using the solution technique of MacCready (2007), the along-channel velocity $u(x, z, t)$ can be divided into depth-averaged (overbar) and deviations from depthaveraged (prime) components so that $u=\bar{u}+u^{\prime}$. The quantity $\bar{u}=Q_{r} / A$ where $Q_{r}$ is the river discharge and $A$ is the cross-sectional area. The quantity $u^{\prime}$ has the standard vertical profile as described in MacCready (2004):

$$
u^{\prime}=\underbrace{\bar{u} P_{1}}_{(a)}+\underbrace{u_{E} P_{2}}_{(b)}
$$

Where

$$
P_{1}=\frac{1}{2}-\frac{3}{2}\left(\frac{z}{h}\right)^{2} \quad \text { and } \quad P_{2}=1-9\left(\frac{z}{h}\right)^{2}-8\left(\frac{z}{h}\right)^{3}
$$

The magnitude of the exchange flow is $u_{E}=g \beta \bar{s}_{x} H^{3} /\left(48 K_{m}\right), H$ is the channel depth, $g$ is the acceleration of gravity, and $K_{m}$ is the vertical eddy viscosity. For simplicity, the density anomaly in the solution is assumed to depend only on salinity $\left(\rho=\rho_{0}(1+\beta S)\right.$, where $\left.\beta=0.77 \times 10^{-3}\right)$. The depth-averaged along-estuary salinity gradient $\bar{s}_{x}$ is set to be constant in the HR65 solution. Here we use the solution of MacCready (2004) (Eq. 7) which allows $\bar{s}_{x}$ to vary along the estuary. Following MacCready (2007), we assume that $K_{m}=a_{0} C_{d} U_{t} H$, where $C_{d}$ is a drag coefficient 
$1 \quad\left(=2.6 \times 10^{-3}\right)$ and $a_{0}$ is a tuning coefficient (0.0325 in MacCready (2007), but 0.0227 in this study). Part (a) in Eq. (5) represents the circulation contributed by river discharge (RV), and part (b) represents the circulation contributed by pressure gradient (PG). Channel depth and width are prescribed based on the realistic conditions in the upper Chesapeake Bay. In the following, we use $s_{o c n}$ to represent the oceanic salinity, which are based on observations at Station CB4.4 (Fig. 15.1). Based on our 3D model configuration, we choose river discharge values of $2400 \mathrm{~m}^{3} \mathrm{~s}^{-1}$ and $800 \mathrm{~m}^{3} \mathrm{~s}^{-1}$, which largely represent the conditions of high-discharge and low-discharge periods, respectively. Using the linear adjustment time theory of MacCready (2007), the salt intrusion length can be scaled by $L \propto 2 \int_{R}^{0} \frac{\bar{s}}{s_{o c n}} d x$ and the freshwater replacement time can be approximated by $\frac{1}{2} \frac{L}{\bar{u}}$. When river discharge is $2400 \mathrm{~m}^{3} \mathrm{~s}^{-1}\left(800 \mathrm{~m}^{3} \mathrm{~s}^{-1}\right)$, the freshwater replacement time is about 15.2 (56.0) days, and the salt intrusion length is about $104 \mathrm{~km}(128$ $\mathrm{km})$. The estimated freshwater replacement timescales are quite consistent with the water ages at the mouth calculated by Exp.1 which represents the mean transport timescale of the freshwater from the Susquehanna River. As the freshwater moves downstream, it replaces the old water. For transport of water from the lower Bay, the transport timescale depends on the exchange flow. The Knudsen relation provides a suitable estimation of the exchange flow from a given stratification. For $\bar{u} \square u_{E}$, the dimensionless stratification is estimated by $\Phi=\frac{s_{b o t}-s_{t o p}}{s_{o c n}}=\frac{3}{20} u_{E} \frac{H^{2}}{K_{s}} \frac{\bar{s}_{x}}{s_{o c n}}\left(K_{s}\right.$ is the vertical eddy diffusivity, which has the same definition as Eq. 3.9 in MacCready (2007)). A dimensionless expression for the exchange flow can be written as $\frac{u_{E}}{c}=\frac{1}{48} \frac{c H^{2}}{K_{M}} \frac{1}{L}$, where $c=\sqrt{g \beta s_{o c n} H}$ is twice the speed of the fastest internal wave that could be supported in the estuary given the density difference between ocean and freshwater. Following the methodology of MacCready and Geyer (2010) and using the theoretical solution, the graphical presentation of these scaling results is shown in the plane of $\left(u_{E} / c, \Phi\right)$ (Fig. 16). The Knudsen relation is purely diagnostic. It tells us only which exchange flow is consistent with a given stratification. On its own, it cannot predict both stratification and exchange. Meanwhile, our 3D model results are sampled to calculate the dimensionless exchange flow and stratification 
1

under various real forcing conditions. The $3 \mathrm{D}$ model results largely match the theoretical results (Fig. 16). It is indicated that in the upper Chesapeake Bay stronger exchange flow corresponds to stronger stratification. During the high salinity water intrusion events, the horizontal salinity gradients increase and both the vertical stratifications and exchange flow becomes stronger. Therefore, the age of the water mass coming from thelower Bay is relatively smaller.

\subsection{Renewal of Baltimore Harbor}

Persistent low DO during the summer in the deep-water (dead zone) of the main Bay remains a serious concern for water quality managers. Observations indicate that the hypoxic or anoxic water in the deep channel of the main Bay can enter most of the major tributaries due to gravitational circulation (Kuo and Neilson, 1987). This phenomenon has been observed in the Baltimore Harbor, which greatly degrades the ecosystem in the inner Harbor. In the experiment of tracing deep water coming from the lower Bay, we find the upper layer tracer concentration near the head of the Harbor is higher than that in the inner and outer Harbor (figure not shown). The age distribution (Figs. 7c-d and Fig. 10) suggests that, in the upper layer of the water column, the time needed for the deep water of the lower Bay to reach the head of the Harbor is less than that to the inner and outer Harbor. According to Cameron and Pritchard (1963), the characteristic salinity distribution of the Harbor has a positive seaward gradient in the lower layer, but a negative seaward gradient nearer the surface. The resulting stratification is weakest near the head of the Harbor, where vertical mixing is stronger than in other areas of the Harbor. The increased vertical mixing (or upwelling) near the head of the Harbor may facilitate the upward transport of dissolved substances in that area.

Although the concentrations of riverine pollutants entering the Harbor are higher during the high-discharge period than that during the low-discharge period, the renewal of water in the Harbor is faster during the high-discharge period than that during the low-discharge period. Thus, the impact of dissolved riverine pollutants on the Harbor is not severe during the highdischarge period as large amounts of substances will be transported out of the Harbor quickly. The worst situation can occur at the end of the high-discharge period when the concentrations in the Harbor are still high but the water renewal is slowing down.

\section{Conclusions}


The water exchange between the Baltimore Harbor and Chesapeake Bay is investigated using artificial tracer in conjunction with a calibrated realistic 3D model. The tracer concentration is representative of water or dissolved substances coming from the concerned source region, while the water age can indicate the transport timescale of these dissolved substances. These features are important factors that need to be examined when trying to protect the tidal environmental resources and manage pollutant transport in estuaries.

The results suggest that the temporal and spatial variations of water exchange between the Harbor and the Bay have obvious seasonal features, which are highly correlated with the Susquehanna River discharge. The hydrodynamic condition during the high-discharge period facilitates the intrusion of dissolved substances coming from Susquehanna River to the Harbor (mainly via the upper layer of the water column). For the case of releasing tracers from Susquehanna River (Exp. 1), the tracer concentrations increase approximately 40\%, but the water age decreases approximately 2 months during a high-discharge period compared to the results during a low-discharge period. Both the upper and lower layers are dominant pathways for transporting dissolved substances from the Susquehanna River to the Harbor, but the upper layer tends to transport water masses with higher concentrations of dissolved substances.

During a high-discharge period, the salinity decreases in the upper Bay and the baroclinic pressure between the Bay and the Harbor decreases, which suppresses the saline water intrusion to the Harbor thus decreases the transport time of water coming from the lower Bay (Exp. 2). Compared to a high-discharge period, the tracer concentration decreases about $20 \%$ and the water age increases about 20 days during a low-discharge period. Only the lower layer is the dominant pathway of transporting dissolved substances coming from the lower Bay into the Harbor.

The transport in the main channel is highly related to the dynamic conditions in the lower Bay. A high-salinity water intrusion event in the bottom layer of the Bay usually corresponds to a low water age event near the bottom both in the Bay and in the Harbor. The transport time depends on the strength of the exchange flow. The water age decreases by approximately 20 days when the landward residual velocity in the main Bay increases by approximately $8 \mathrm{~cm} / \mathrm{s}$. Diagnostic analyses suggest that the low river discharge and strong along-Bay pressure gradient facilitate the up-Bay transport of dissolved substance coming from the lower Bay. 
The time needed for the contaminants in the Harbor to be transported to the main Bay during a typical low-discharge period is about 1 month longer than during a typical highdischarge period. Because of the development of the three-layered circulation, dissolved substances usually remain the longest in the mid-depth of the Harbor. The maximum tracer concentration occurs at around $6 \mathrm{~m}$ depth in the area close to the mouth of the Harbor. As soon as the dissolved substances are transported out of the Harbor, water mass follows two different pathways. When being transported toward the downstream of the Bay, high tracer concentrations occur near the surface. Conversely, when being transported toward the upstream of the Bay, high tracer concentrations occur near the bottom.

The long-term mean transport processes, which mainly depend on the low frequency and mean motion of the water, are essential to evaluate water exchange between the Harbor and the Bay. This study indicates that the water age and tracer concentration in the Harbor are sensitive to the perturbations of the Susquehanna River discharge. In reality, the perturbation can also be induced by the wind forcing. and affect the water exchange over shorter timescales. The incorporation of the wind effect will be covered in our future work. As the freshwater discharge dominates stratification in the upper Bay, the results presented in this study represents the seasonal density-driven exchange flow between the Harbor and the Bay. The approach used here can be used to study the water exchange processes in other estuaries and harbors.

\section{Acknowledgements}

The funding of the project is provided by the Maryland Department of Environment. This is the contribution number \#xxx of Virginia Institute of Marine Sciences, College of William and Mary. This work was performed using computational facilities at the College of William and Mary which were enabled by grants from Sun Microsystems, the National Science Foundation, and Virginia's Commonwealth Technology Research Fund.

\section{References}

Austin, J.A., 2002. Estimating the mean ocean-bay exchange rate of the Chesapeake Bay. Journal of Geophysical Research 110 (C11), 3192.

Boicourt, W.C., and Olson, P., 1982. A hydrodynamic study of the Baltimore Harbor system. Tech. Rep. 82-10, Chesapeake Bay Institute, The Johns Hopkins University, 131 pp. 
Cameron, W.M., and Pritchard, D.W., 1963. Estuaries, p.306-324. In The Sea - Vol. 2. Ed. By M.N. Hill. Interscience, New York, N.Y., 757 pp.

Carpenter, J. H. 1960. The Chesapeake Bay Institute study of the Baltimore Harbor, p. 62-78. In Proc. $33^{\text {rd }}$ Ann. Conf. Maryland-Delaware Water and Sewage Assoc.

Chao, S.-Y., Boicourt, W.C., Wang, H. V., 1996. Three layered circulation in reverse estuaries. Continental Shelf Research 16, 1379-1397.

Deleersnijder, E., Campin, J., Delhez, E., 2001. The concept of age in marine modeling I. Theory and preliminary model results. Journal of Marine Systems 28, 229-267.

Delhez, E. J. M., J.M. Campin, A.C. Hirst, E. Deleersnijder, 1999. Toward a general theory of the age in ocean modeling. Ocean Modeling 1, 17-27.

Delhez, E. J. M., Deleersnijder, E., 2002. The concept of age in marine modeling II. Concentration distribution function in the English Channel and the North Sea. Journal of Marine Systems 31, 279-297.

DÖÖs, K., Engqvist, A., 2007. Assessment of water exchange between a discharge region and the open sea - A comparison of different methodological concepts. Estuarine, Coastal and Shelf Science 74,709721.

Geyer, W.R., Trowbridge, J.H., and Bowen, M.M., 2000. The dynamics of a partially mixed estuary. Journal of Physical Oceanography 30, 2035-2048.

Gustafsson, K. E., Bendtsen, J., 2007. Elucidating the dynamics and mixing agents of a shallow fjord through age tracer modeling. Estuarine, Coastal and Shelf Science 74, 641-654.

Hansen, D.V., and Rattray, Jr. M., 1965. Gravitational circulation in straits and estuaries. Journal of Marine Research 23, 104-122.

Hirst, A. C., 1999. Determination of water component age in ocean models: application to the fate of North Atlantic Deep Water. Ocean Modelling 1, 81-94.

Hood, R.R., Wang, H. V., Purcell, J.E., Houde, E.D., Harding Jr., L.W., 1999. Modeling particles and pelagic organisms in Chesapeake Bay: Convergent features control plankton distributions. Journal of Geophysical Research 104, 1223-1243.

Johnson, B.H. et al., 1991. User's guide for a three-dimensional numerical hydrodynamic model of Chesapeake Bay. Department of the army, Waterways experiment station, Corps of Engineers.

Johnson, B. H., Kim, K.W., Heath, R.E., Hsieh, B.B., Butler, H. L., 1993. Validation of threedimensional hydrodynamic model of Chesapeake Bay. Journal of Hydraulic Engineer 119, 2-20.

Johnson, B. H., Wang, H. V., Kim, K. W., 1995. Can numerical estuarine models be driven at the estuary mouth, in: ASCE Estuarine and Coastal Modeling, pp. 255-267, Am. Soc. Of Civ. Eng., New York.

Kemp, W.M., W.R. Boynton, J.E. Adolf, D.F. Boesch, W.C. Boicourt, G. Brush, J.C. Cornwell, T.R. Fisher, P.M. Gilbert, J.D. Hagy, L. W. Harding, E.D. Houde, D.G. Kimmel, W.D. Miller, R.I.E. Newell, 
M.R. Roman, E.M. Smith, and J.C. Stevenson, 2005. Eutrophication of Chesapeake Bay: historical trends and ecological interactions. Marine Ecology Progress Series 30321: 1-29.

Kundu, P. K., 1980. A numerical investigation of mixed-layer dynamics, Journal of Physical Oceanography 10, 220-236.

Kuo, A.Y., and B.J. Neilson, 1987. Hypoxia and salinity in Virginia Estuaries. Estuaries 104: 277-283, doi:10.2307/1351884.

Lin, J., Wang, H. V., Sisson, G. M., Shen, J., 2004. Toxic modeling in an industrial Harbor - A case study for Baltimore Harbor. Proceedings of the Eight International Conference of Estuarine and coastal modeling. November 3-5, 2003, Monterey, CA, 455-474.

Liu, Y., P. MacCready, B. M. Hickey, E. P. Dever, P.M. Kosro, and N. S. Banas, 2009. Evaluation of a coastal ocean circulation model for the Columbia River plume in 2004. Journal of Geophysical Research 114, C00B04, doi: 10.1029/2008JC004929.

MacCready, P., 2004. Toward a Unified Theory of Tidally-Averaged Estuarine Salinity Structure. Estuaries 27, 561-570.

MacCready, P., 2007. Estuarine Adjustment. Journal of Physical Oceanography 37, 2133-2145.

MacCready, P., N. S. Banas, B. H. Jickey, E. P. Dever, Y. Liu, 2009. A model study of tide- and windinduced mixing in the Columbia River Estuary and plume. Continental Shelf Research 29, 278-291.

MacCready, P. and W.R. Geyer, 2010. Advances in Estuarine Physics. Annual Review of Marine Science 2, 35-58, 10.1146/annurev-marine-120308-081015.

Park, K., H. V. Wang, S. Kim, 2008. A model study of the estuarine turbidity maximum along the main channel of the Upper Chesapeake Bay, Estuaries and Coasts 31, 115-133.

Prandle, D. A., 1984. A modeling study of the mixing of 137Cs in the seas of European continent shelf. Philosophical Transactions of Royal Society of London 310, 407-436.

Pritchard, D.W., 1956. The dynamic structure of a coastal plain estuary. Journal of Marine Research 15(I), 33-42.

Sanford, L.P., S.E. Suttles, J. P. Halka, 2001. Reconsidering the physics of the Chesapeake Bay estuarine turbidity maximum. Estuaries 24, 655-669.

Schubel, J.R., Pritchard, D.W., 1986. Responses of upper Chesapeake bay to variations in discharge of the Susquehanna River. Estuaries 9, 236-249.

Shen, J., Haas, L., 2004. Calculating age and residence time in the tidal York River using threedimensional model experiments. Estuarine, Coastal and Shelf Science 61, 449-461.

Shen, J., Wang, H. V., 2007. Determining the age of water and long-term transport timescale of the Chesapeake Bay. Estuarine, Coastal and Shelf Science 74, 750-763.

Sheng, Y.P., 1986. A three-dimensional mathematical model of coastal estuarine and lake currents using a boundary fitted grid, Rep. No. 585, ARAR Group of Titan Syst., Princeton, N.J.. 
Stroup, E. E., D. W. Pritchard, J. H. Carpenter, 1961. Final report, Baltimore Harbor Study. The John Hopkins University Tech. Rep. XXVI, Ref. 61-5. Chesapeake Bay Institute, Baltimore, MD. 79p.

Wang, H. V., Chapman, R. S., 1995. Application of vertical turbulence closure Schemes in the Chesapeake Bay Circulation Model - A comparative study, in ASCE Estuarine and Coastal Modeling, pp. 283-297, Am. Soc. Civ. Eng., New York.

Wang, H.V., H. Liu, K. Park. 2004. The development of a water quality model for Baltimore Harbor, Back River, and the adjacent upper Chesapeake Bay. A report to Maryland Department of the Environment, SRAMSOE 386. Gloucester Point, VA: Virginia Institute of Marine Science.

Xu, J., Chao, S.-Y., Hood, R.R., Wang, H., Boicourt, W.C., 2002. Assimilating high-resolution salinity data into a model for a partially mixed estuary. Journal of Geophysical Research 107 (C7), 3074, doi: 10.1029/2000JC000626.

Xu, J., and Hood, R.R., 2006. Modeling biogeochemical cycles in Chesapeake Bay with a couple physical-biological model. Estuarine, Coastal and Shelf Science 69, 19-46.

Zimmerman, J. T. F., 1976. Mixing and flushing of tidal embayments in the western Dutch Wadden sea, Part I: distribution of salinity and calculation of mixing time scales. Netherlands Journal of Sea Research 10, 149-191.

\section{Figure Captions}

Figure 1. Bathymetry of upper Chesapeake Bay. The color gradient represents water depth in meters.

Figure 2. Model domain and boundary-fitted computational grids (101 X 153). The red bold lines denote transects along the navigational channel of the Harbor (transect I) and across the mouth of the Harbor (transect II) respectively. The star symbols represent stations where time series analyses are conducted. The rectangle (Station V) in the main channel of the Bay is the sample site of modeled velocity profile. The triangles represent CBP monitoring stations in the Bay.

Figure 3. Model-data comparisons. (a) Salinity results. The subscripts s and b represent surface salinity and bottom salinity, respectively ; (b) low-pass filtered water elevation. The observations (black line) are missing in some time intervals. The correlation coefficients (CC) in (b) are at the 95\% confidence level.

Figure 4. Long-term mean (1985-2007) daily freshwater discharge $\left(x 10^{3} \mathrm{~m}^{3} \mathrm{~s}^{-1}\right)$ from Susquehanna River.

Figure 5. (a) Typical longitudinal-vertical section of the salinity (ppt) distribution along the navigational channel of the Baltimore Harbor, with the Chesapeake Bay lies in the right entrance of the figure. Arrows indicate the schematic depiction of the three-layered circulation pattern in the Harbor (after Cameron and Pritchard, 1963). (b) Modeled salinity (ppt) profile along transect I. (c) Modeled velocity ( $\mathrm{cm} \mathrm{s}^{-1}$ ) profile along section I. The positive (negative) values represent the outward (inward) flow. The abscissa is consistent with model grid coordinates in Figure 2. 
Figure 6. Surface salinity (ppt) in the upper Chesapeake Bay averaged during (a) the typical highdischarge period and (b) the typical low-discharge period. Zonal velocity $\left(\mathrm{cm} \mathrm{s}^{-1}\right)$ profiles across the mouth of Baltimore Harbor (transect II in Fig. 2) averaged during (c) the typical high-discharge period and (d) the typical low-discharge period. The positive (negative) values represent the outward (inward) flow. The contour interval is $1 \mathrm{ppt}$ for salinity field and $0.5 \mathrm{~cm} \mathrm{~s}^{-1}$ for the velocity field.

Figure 7. Snapshot of surface water age (day) (Exp. 1 (a-b) and Exp. 2 (c-d)) and velocity ( $\left.\mathrm{cm} \mathrm{s}^{-1}\right)$ (e-f) at Day 91 (left) and Day 255 (right). The contour interval is 4 days.

Figure 8. Monthly mean vertical profile of water age (day) resulting from Exp.1 along the navigation channel of Baltimore Harbor (transect I in Fig. 2). The contour interval is 5 days. The abscissa is consistent with the model abscissa in Figure 2.

Figure 9. Temporal vertical tracer concentration (arbitrary unit) (left, a-d) and water age (day) (right, e-h) profiles resulting from Exp. 1 at Stations C, D, E and B (from top to bottom), respectively. The contour interval for the tracer concentration and water age are 0.1 and 10 days, respectively. Figure 10. Same as Fig. 8, but for the results of Exp. 2.

Figure 11. Same as Fig. 9, but for the results of Exp. 2.

Figure 12. Temporal evolution of total tracer concentration (arbitrary unit) in Baltimore Harbor under high-flow (thin line) and low-flow (bold line) condition, respectively. The dashed lines indicate where the total tracer concentration is reduced to a factor of $\mathrm{e}^{-1}$ (i.e., measure of the turnover time of the Harbor waters).

Figure 13. Evolution of tracer concentration (arbitrary unit) in the case of releasing tracers instantly in Baltimore Harbor under typical high-discharge condition (Exp. 3). Chesapeake Bay lies to the right of the figure. The abscissa is consistent with the model abscissa in Figure 2.

Figure 14. Time series of depth-averaged tracer concentration under (a) typical high-discharge condition and (b) typical low-discharge condition. The temporal vertical profiles of tracer concentration under typical low-discharge condition are shown in (c). In each row, the results at Stations f, g, and h are presented from the left to the right.

Figure 15. The temporal vertical profile of (a) observed salinity (ppt) at Station CB4.4; (b) water age (day) at Station C (Exp. 2); (c) water age at Station B (Exp. 2); and (d) residual velocity ( $\mathrm{cm} \mathrm{s}^{-1}$ ) at Station $\mathrm{V}$. The negative (positive) velocity represents the seaward (landward) flow.

Figure 16. The plane (uE/c, $\Phi)$ presentation of all possible estuary states. $\Phi$ and $\mathrm{uE} / \mathrm{c}$ denotes the dimensionless stratification and exchange flow, respectively. The solid line represents the results calculated using theoretical solution, the triangle represents the results calculated using the 3D model.

\section{Table}

Table 1. A summary of the tracer age results in the Baltimore Harbor.

\begin{tabular}{|l|l|l|l|}
\hline Description & Exp. 1 & Exp. 2 & Exp. 3 \\
\hline $\begin{array}{l}\text { Vertical age distribution } \\
\text { pattern }\end{array}$ & $\begin{array}{l}\text { Low age occurs at both } \\
\text { surface and bottom, and }\end{array}$ & $\begin{array}{l}\text { Decreases consistently } \\
\text { with depth }\end{array}$ & $\begin{array}{l}\text { Larger in the mid-depth } \\
\text { than those in other areas }\end{array}$ \\
\hline
\end{tabular}




\begin{tabular}{|c|c|c|c|}
\hline & $\begin{array}{l}\text { high age occurs in mid- } \\
\text { depth }\end{array}$ & & \\
\hline $\begin{array}{l}\text { Vertical age difference } \\
(\mathrm{VAD}) \text { in the water } \\
\text { column }\end{array}$ & $\begin{array}{l}\text { The highest (lowest) VAD } \\
\text { can be about } 50 \text { (20) days } \\
\text { and appears in winter } \\
\text { (April) }\end{array}$ & $\begin{array}{l}\text { VAD is about } 40-50 \text { days. } \\
\text { larger than bottom layer }\end{array}$ & Not available \\
\hline $\begin{array}{l}\text { Age variations from high- } \\
\text { discharge condition to low- } \\
\text { discharge condition }\end{array}$ & Increases about 2 months & Decreases about 20 days & $\begin{array}{l}\text { The turnover time of the } \\
\text { Harbor is } 21.7 \text { days ( } 39.5 \\
\text { days) under the high- } \\
\text { discharge (low-discharge) } \\
\text { condition }\end{array}$ \\
\hline $\begin{array}{l}\text { Tracer concentration (TC) } \\
\text { distribution pattern }\end{array}$ & $\begin{array}{l}\text { Decrease with depth. } \\
\text { Highest TC appears in } \\
\text { April }\end{array}$ & $\begin{array}{l}\text { Increase } \text { with depth. } \\
\text { Lowest TC appears in } \\
\text { April }\end{array}$ & $\begin{array}{l}\text { After instantaneous release, } \\
\text { high TC remains for a } \\
\text { longer time in the mid- } \\
\text { depth than those in other } \\
\text { areas }\end{array}$ \\
\hline
\end{tabular}

1 


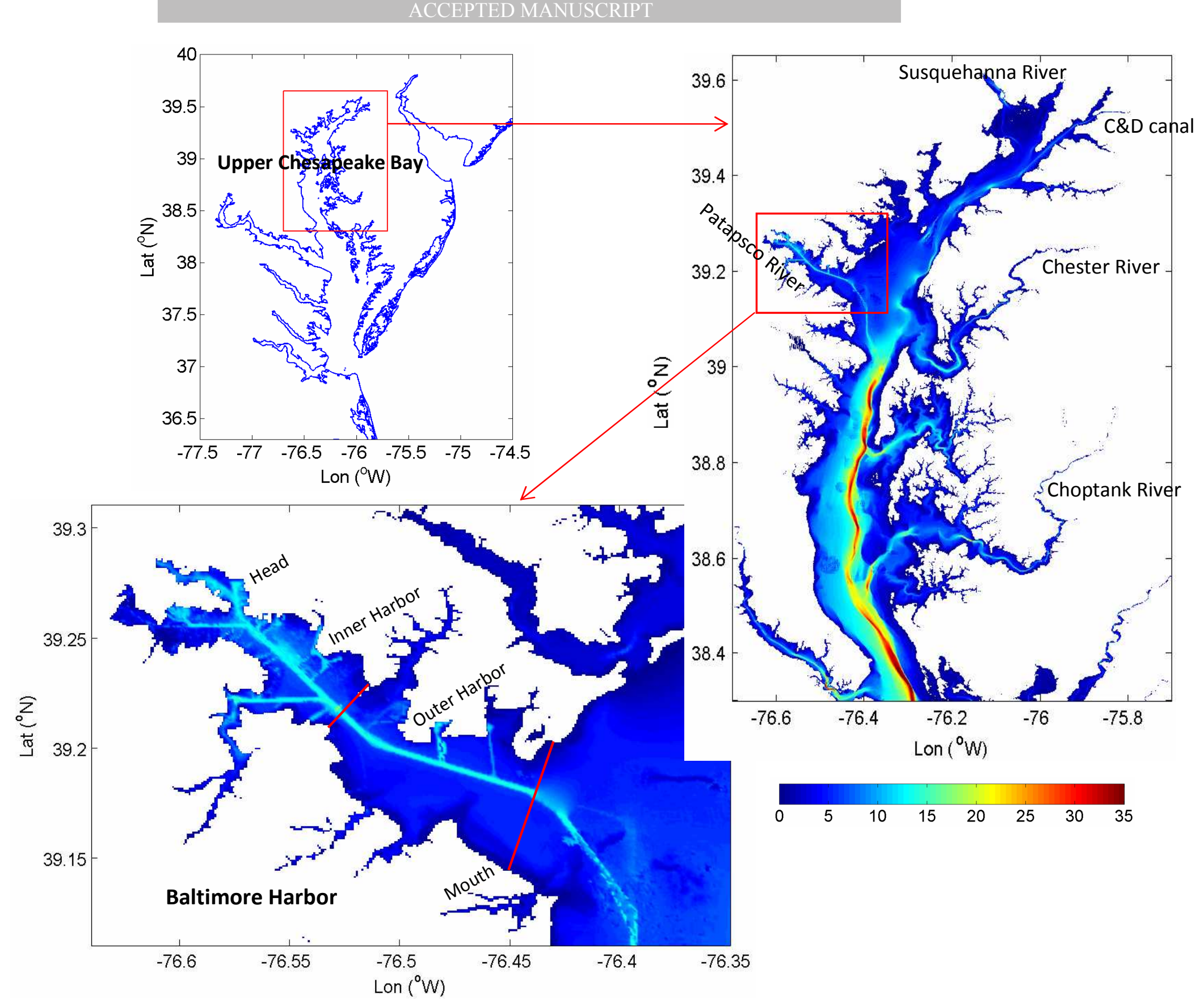

Figure 1. Bathymetry of upper Chesapeake Bay. The color gradient represents water depth in meters. 
Figure 2. Model domain and boundary-fitted computational grids (101 X 153). The red bold lines denote transect along the navigational channel of the Harbor (transect I) and across the mouth of the Harbor (transect II) respectively. The star symbols represent stations where time series analyses are conducted. The rectangle (Station $\mathrm{V}$ ) in the main channel of the Bay is the sample site of modeled velocity profile. The triangles represent CBP monitoring stations in the Bay.

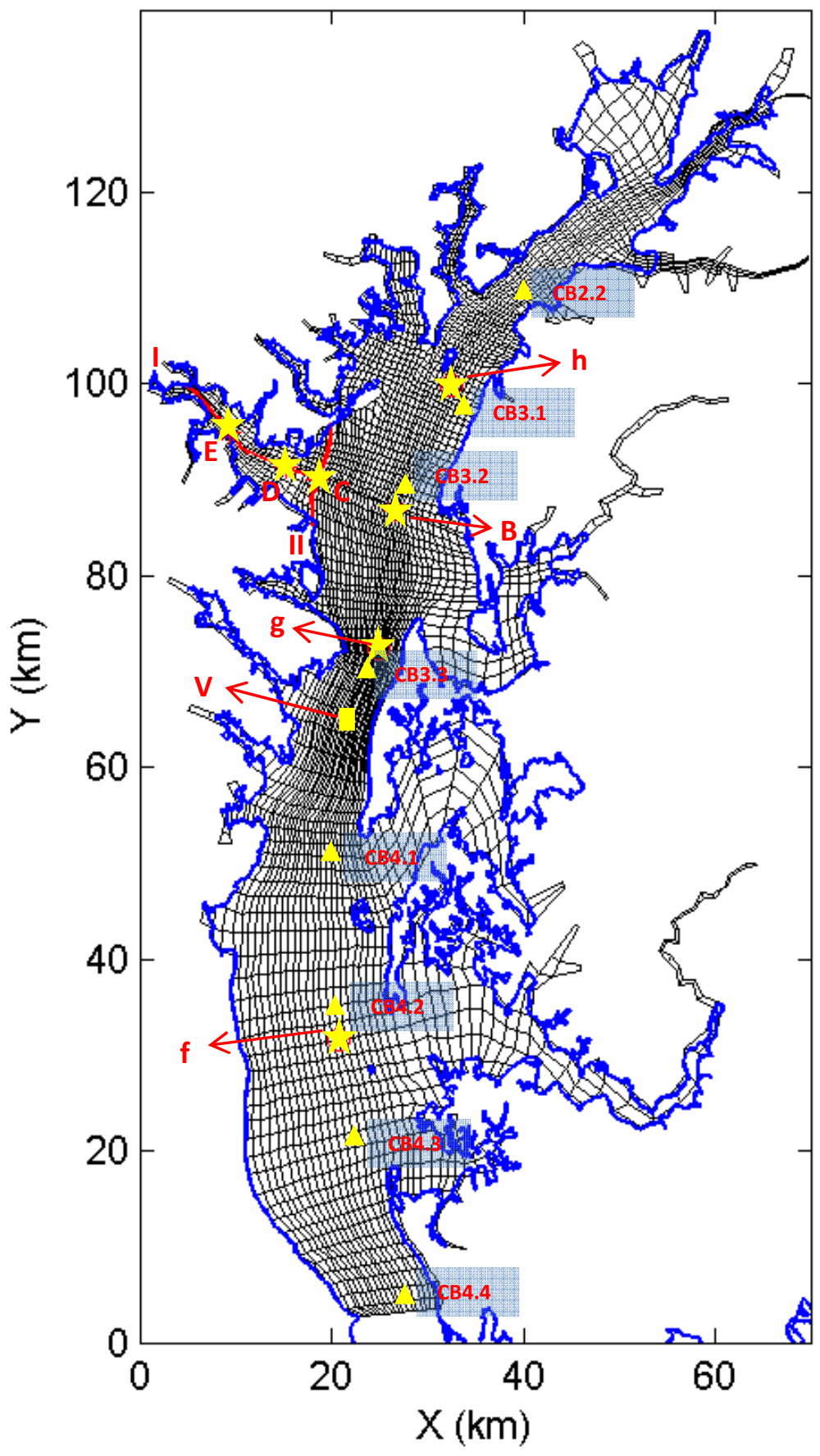


a
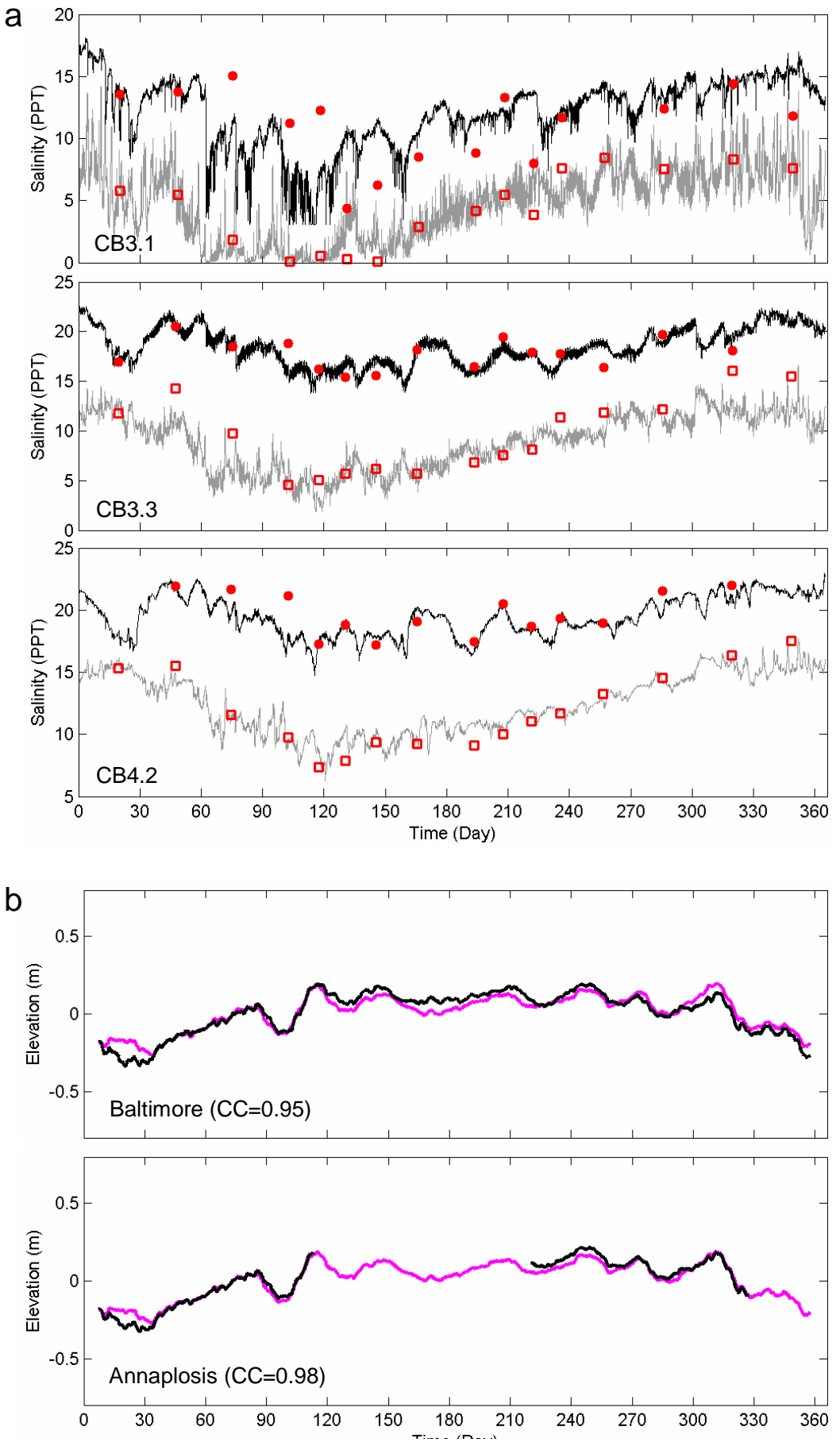
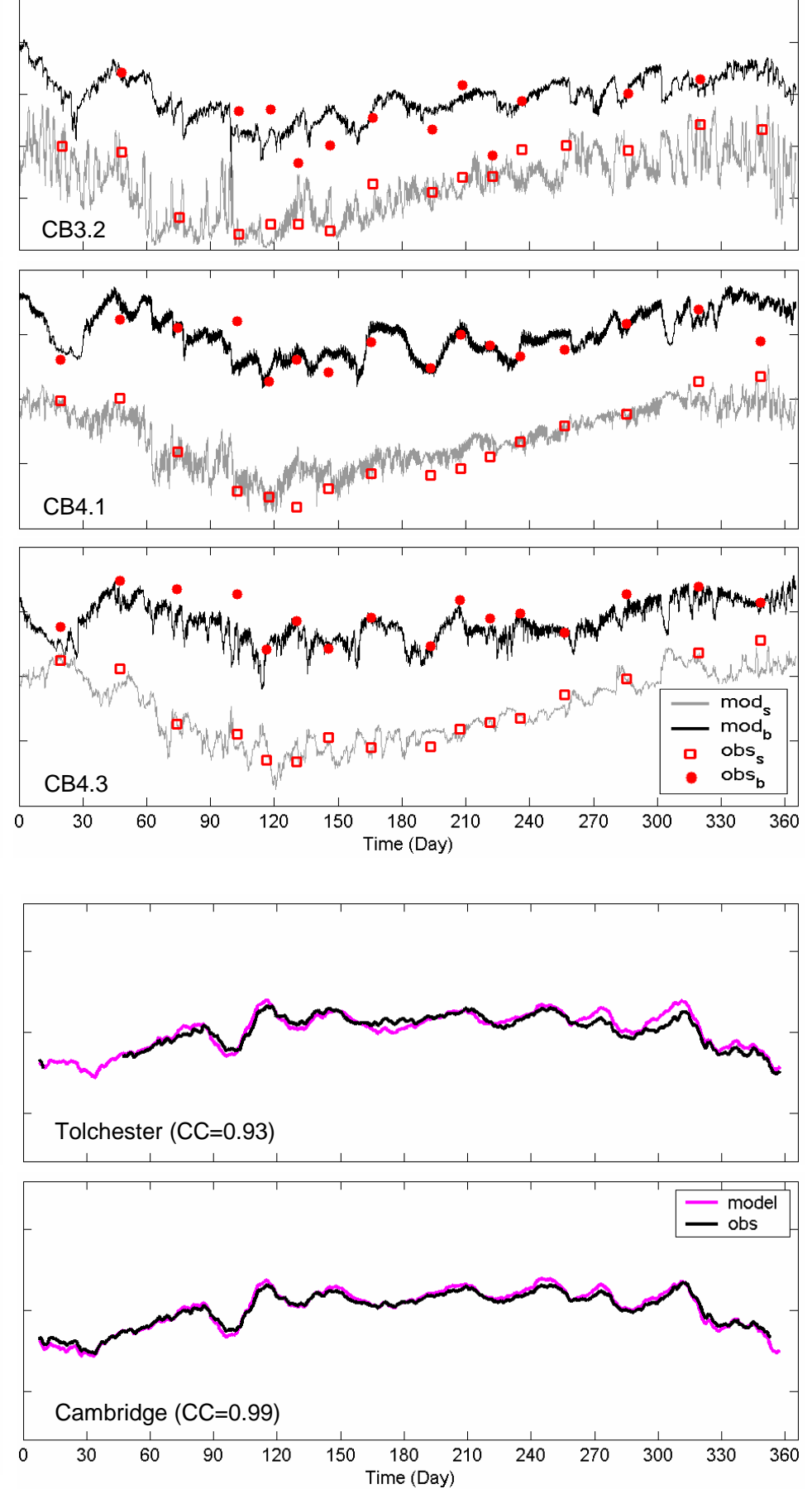

Figure 3. Model-data comparisons. (a)

Salinity results. The subscripts $s$ and $b$ represent surface salinity and bottom salinity, respectively ; (b) low-pass filtered water elevation. The observations (black line) are missing in some time intervals. The correlation coefficients (CC) in (b) are at the $95 \%$ confidence level. 


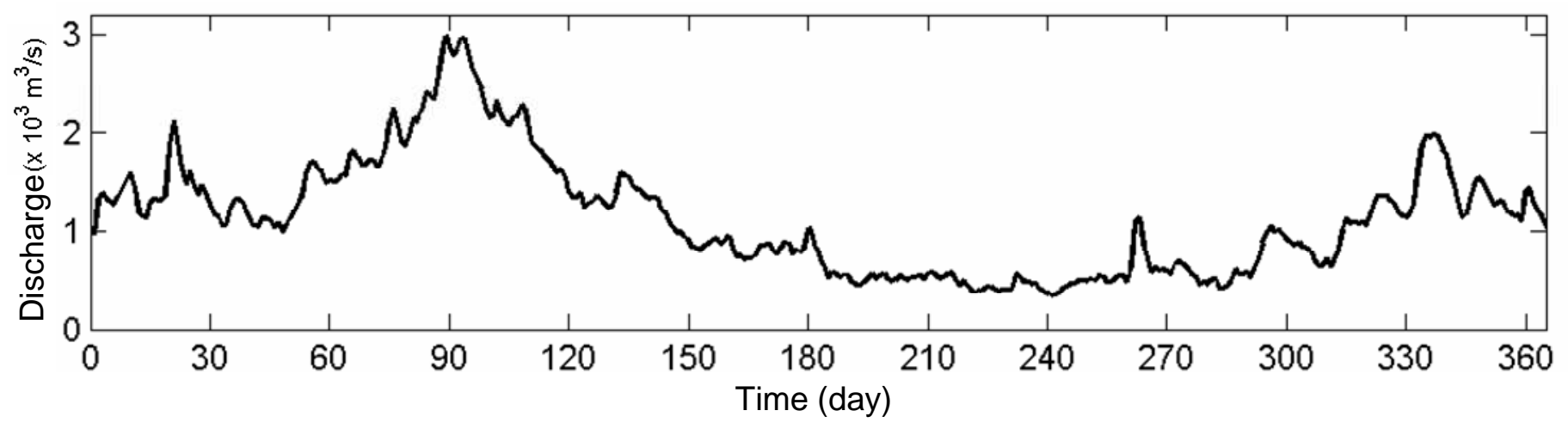

Figure 4. Long-term mean (1985-2007) daily freshwater discharge $\left(\times 10^{3} \mathrm{~m}^{3} \mathrm{~s}^{-1}\right)$ from Susquehanna River. 
(a)
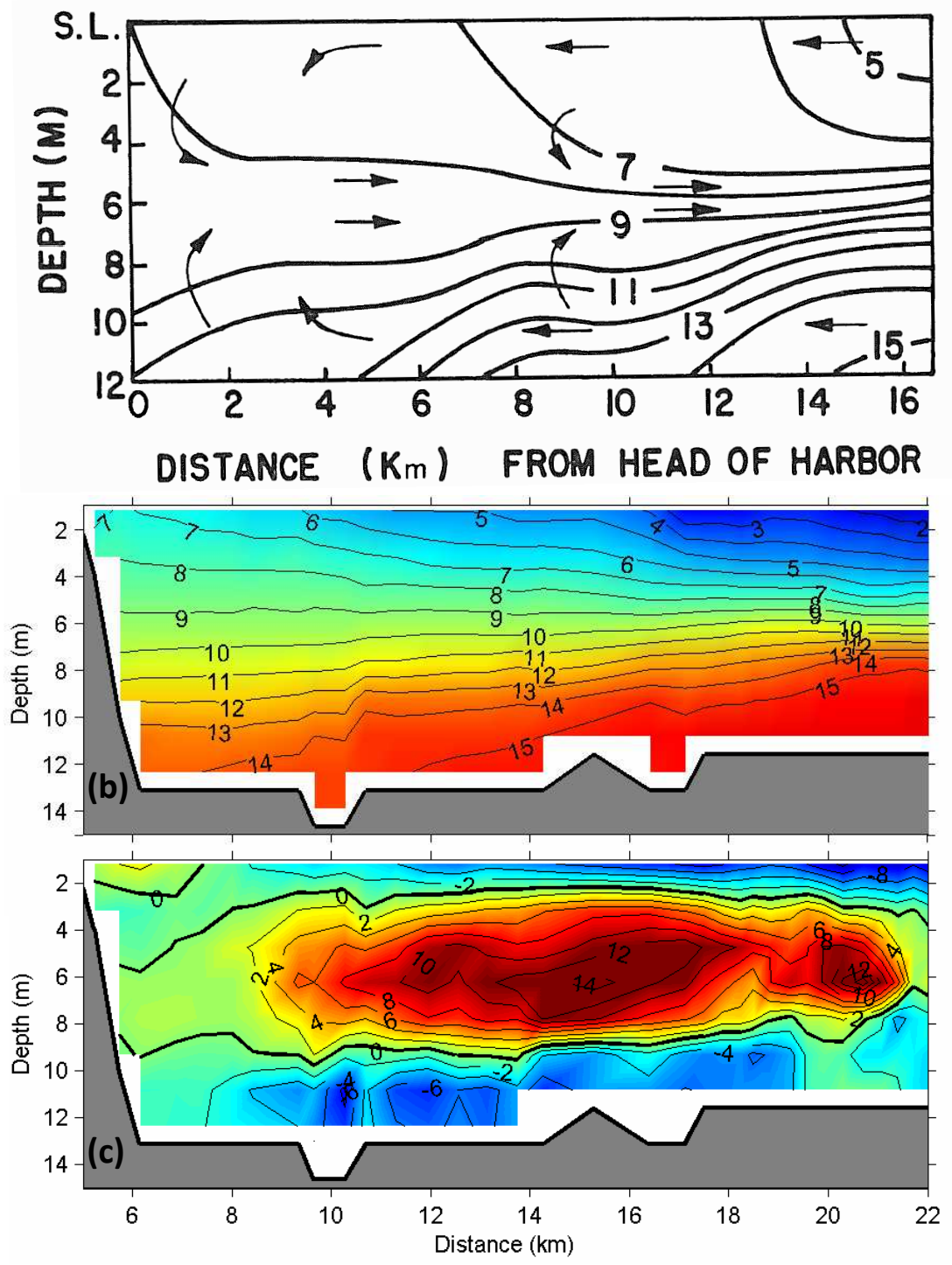

Figure 5. (a) Typical longitudinal-vertical section of the salinity (ppt) distribution along the navigational channel of the Baltimore Harbor; Chesapeake Bay lies to the right of the figure. Arrows indicate the schematic depiction of the three-layered circulation pattern in the Harbor (after Cameron and Pritchard, 1963). (b) Modeled salinity (ppt) profile along transect I. (c) Modeled velocity $\left(\mathrm{cm} \mathrm{s}^{-1}\right)$ profile along transect $\mathrm{I}$. The positive (negative) values represent the outward (inward) flow. The abscissa in (b) and (c) is consistent with the model abscissa in Figure 2. 

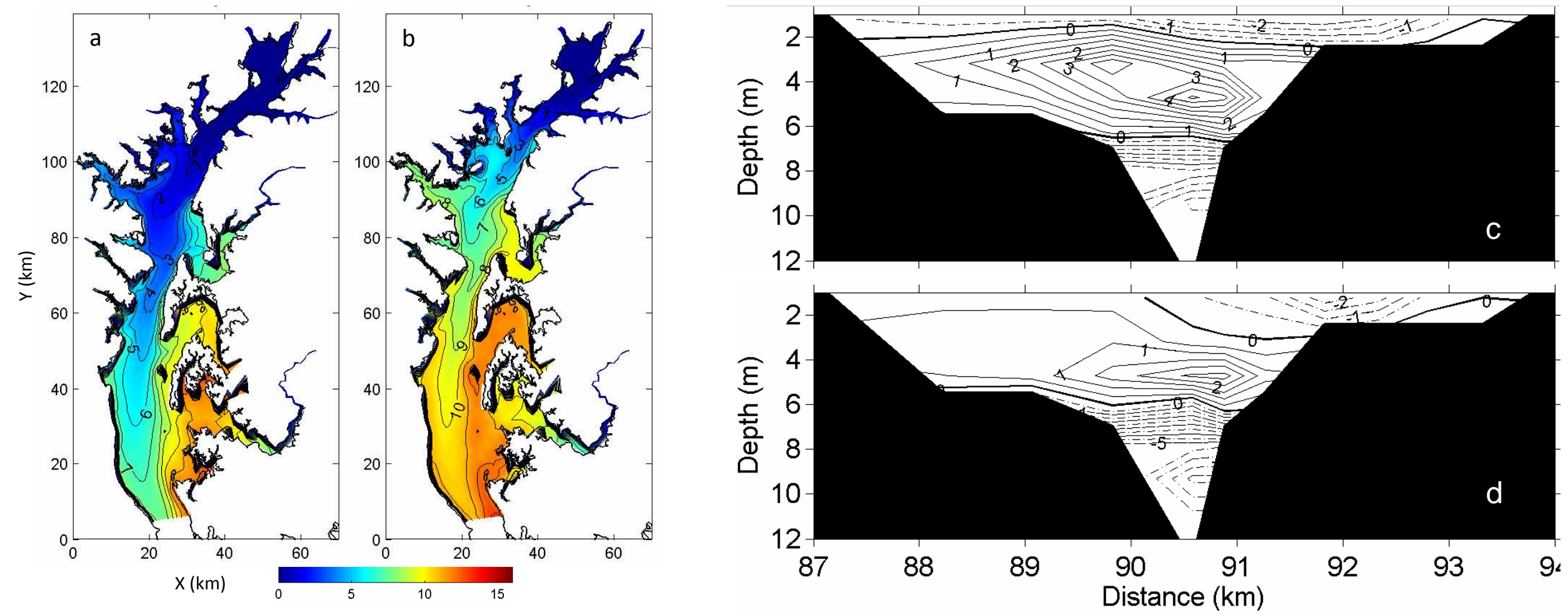

Figure 6. Surface salinity (ppt) in the upper Chesapeake Bay averaged during (a) the typical high-discharge period and (b) the typical low-discharge period. Zonal velocity $\left(\mathrm{cm} \mathrm{s}^{-1}\right)$ profiles across the mouth of Baltimore Harbor (transect II in Fig. 2) averaged during (c) the typical high-discharge period and (d) the typical low-discharge period. The positive (negative) values represent the outward (inward) flow. The contour interval is $1 \mathrm{ppt}$ for salinity field and $0.5 \mathrm{~cm} \mathrm{~s}^{-1}$ for the velocity field. 

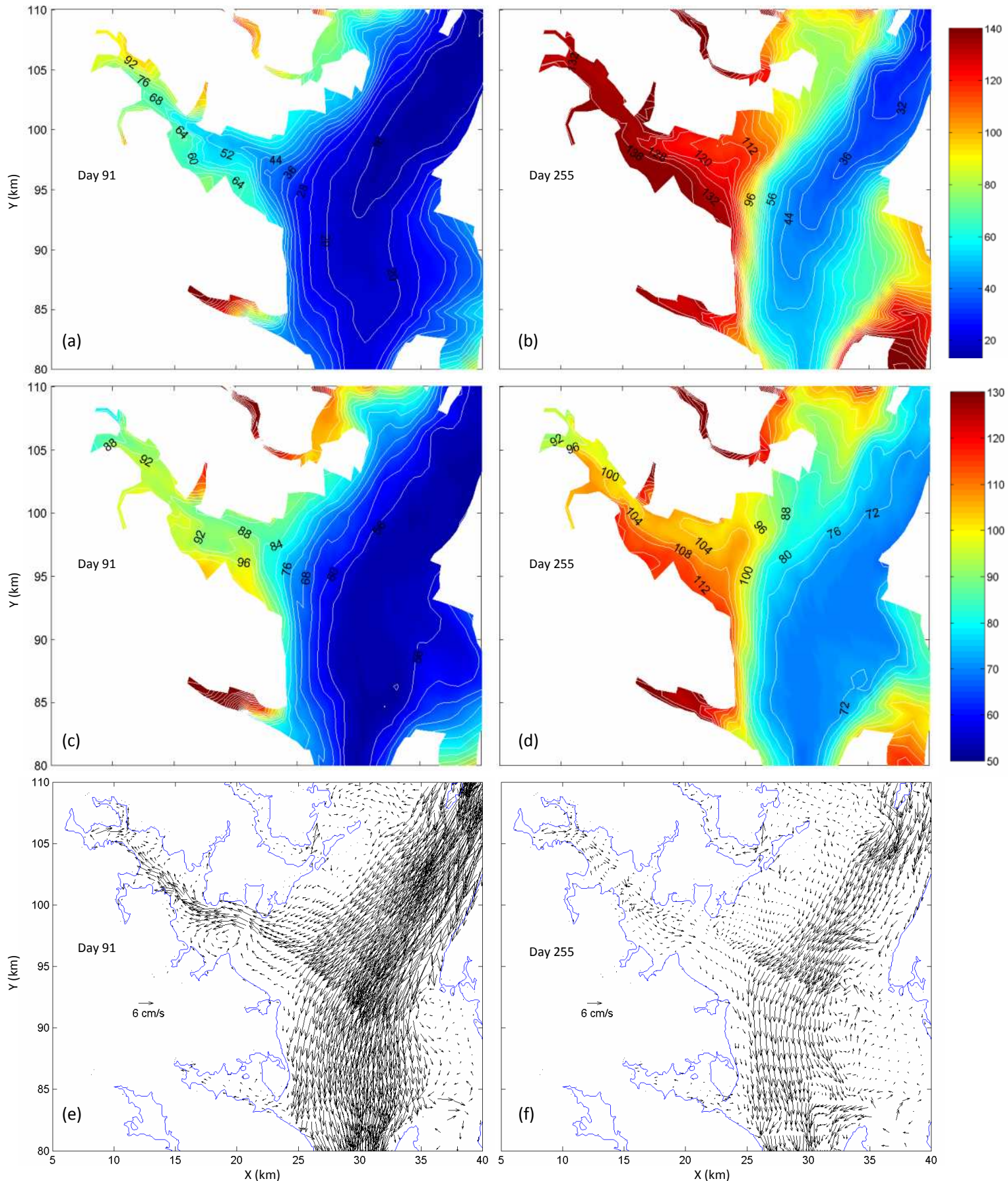

Figure 7. Snapshot of surface water age (day) (Exp. 1 (a-b) and Exp. 2 (c-d)) and velocity $\left(\mathrm{cm} \mathrm{s}^{-1}\right)(\mathrm{e}-\mathrm{f})$ at Day 91 (left) and Day 255 (right). The contour interval is 4 days.

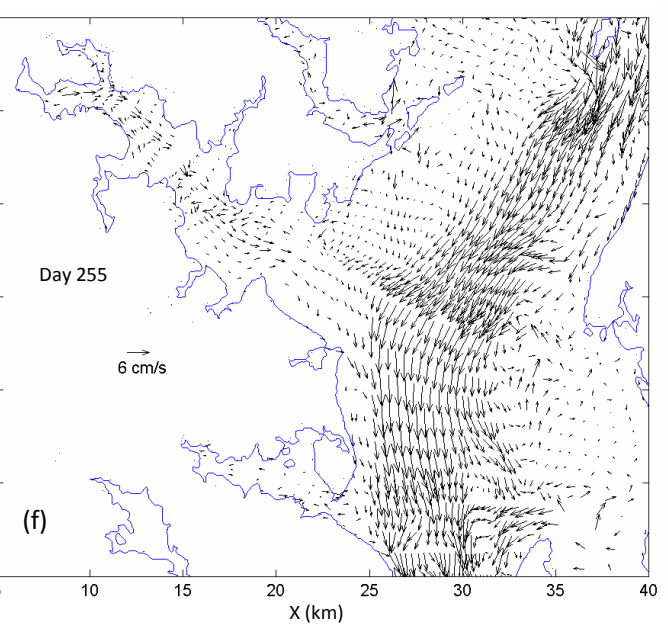



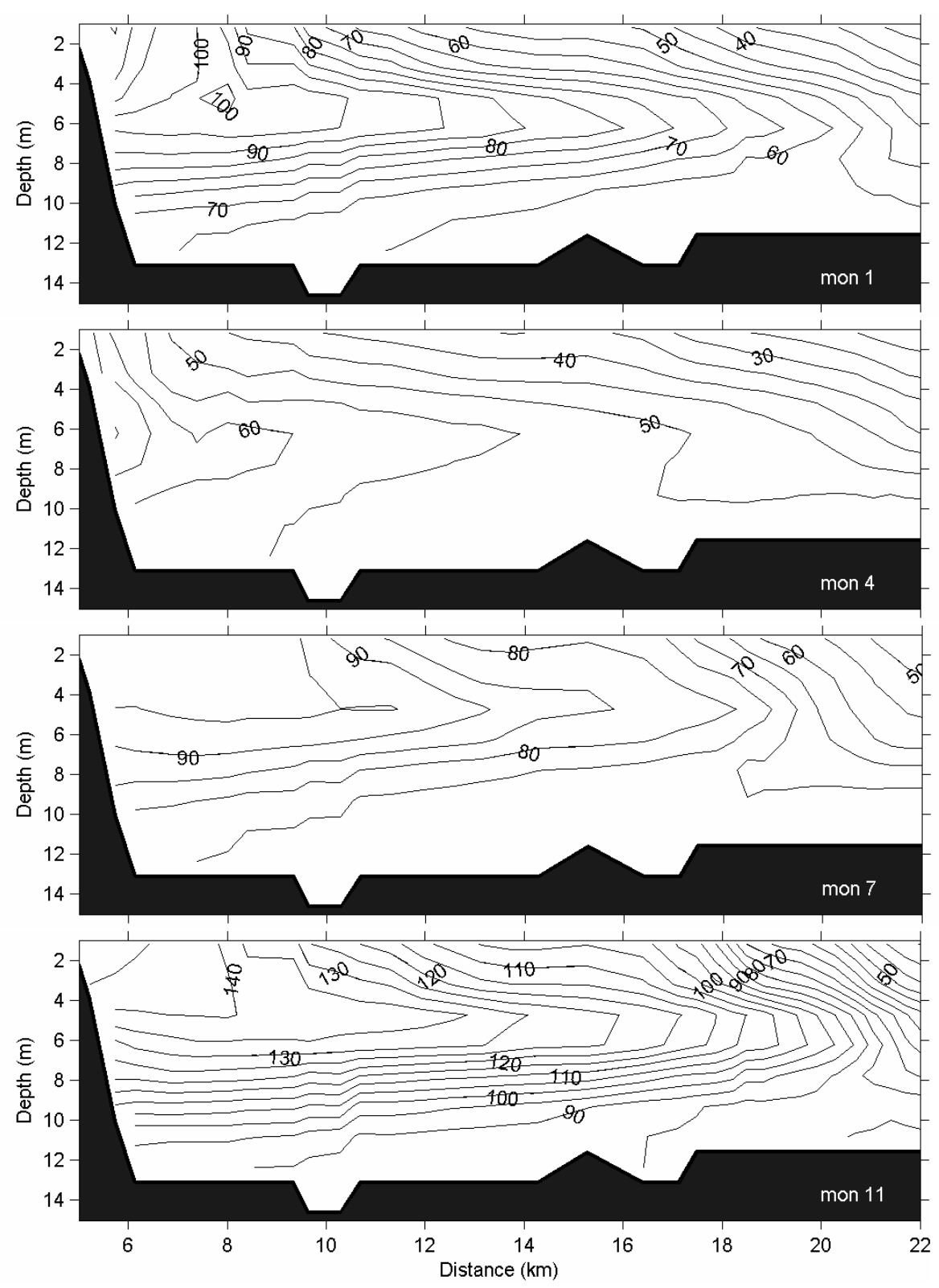

Figure 8. Monthly mean vertical profile of water age (day) resulting from Exp.1 along the navigational channel of Baltimore Harbor (transect I in Fig. 2). The contour interval is 5 days. The abscissa is consistent with the model abscissa in Figure 2. 

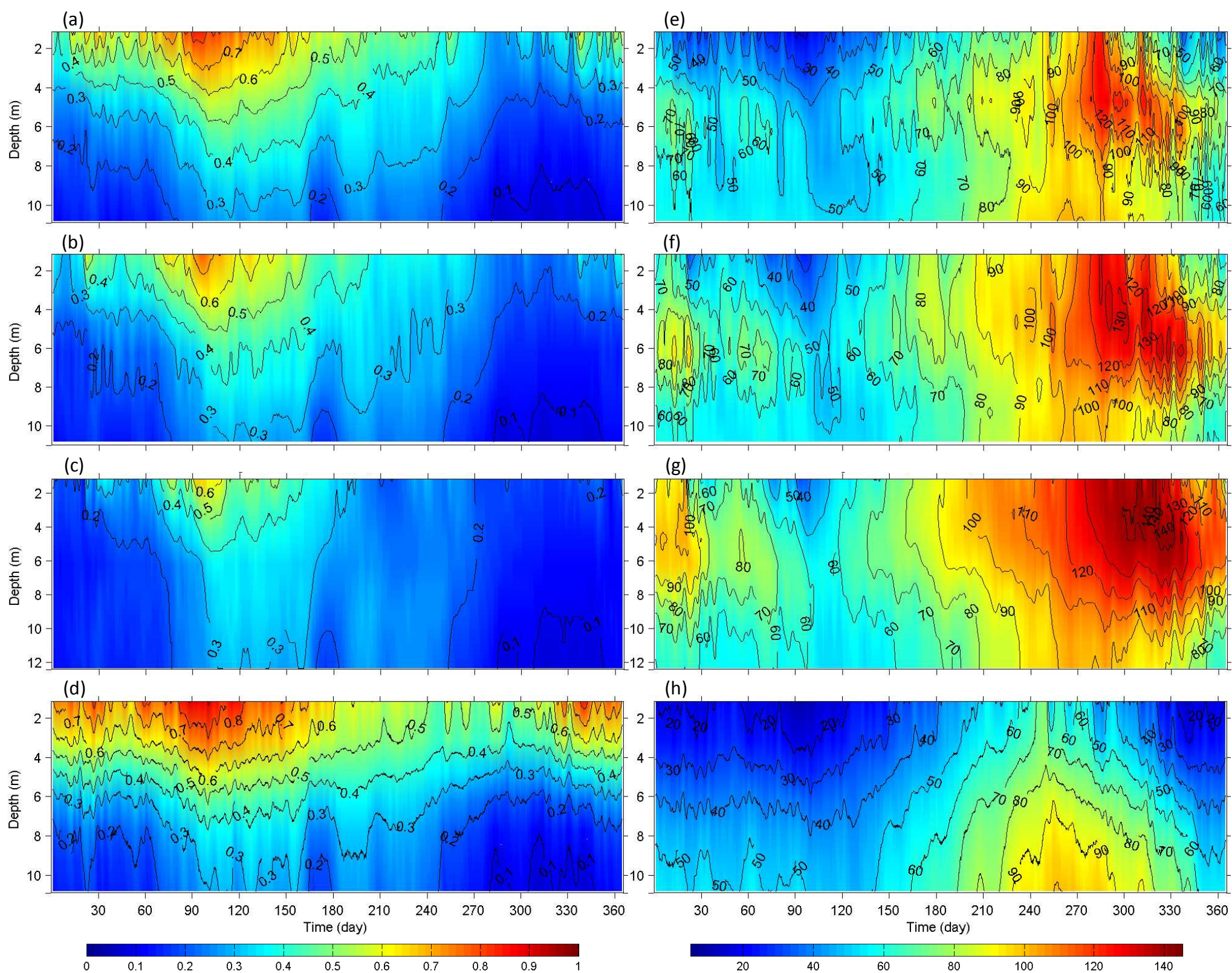

Figure 9. Temporal vertical tracer concentration (arbitrary unit) (left, a-d) and water age (day) (right, e-h) profiles resulting from Exp. 1 at Stations C, D, E, and B (from top to bottom), respectively. The contour intervals for the tracer concentration and water age are 0.1 and 10 days, respectively. 

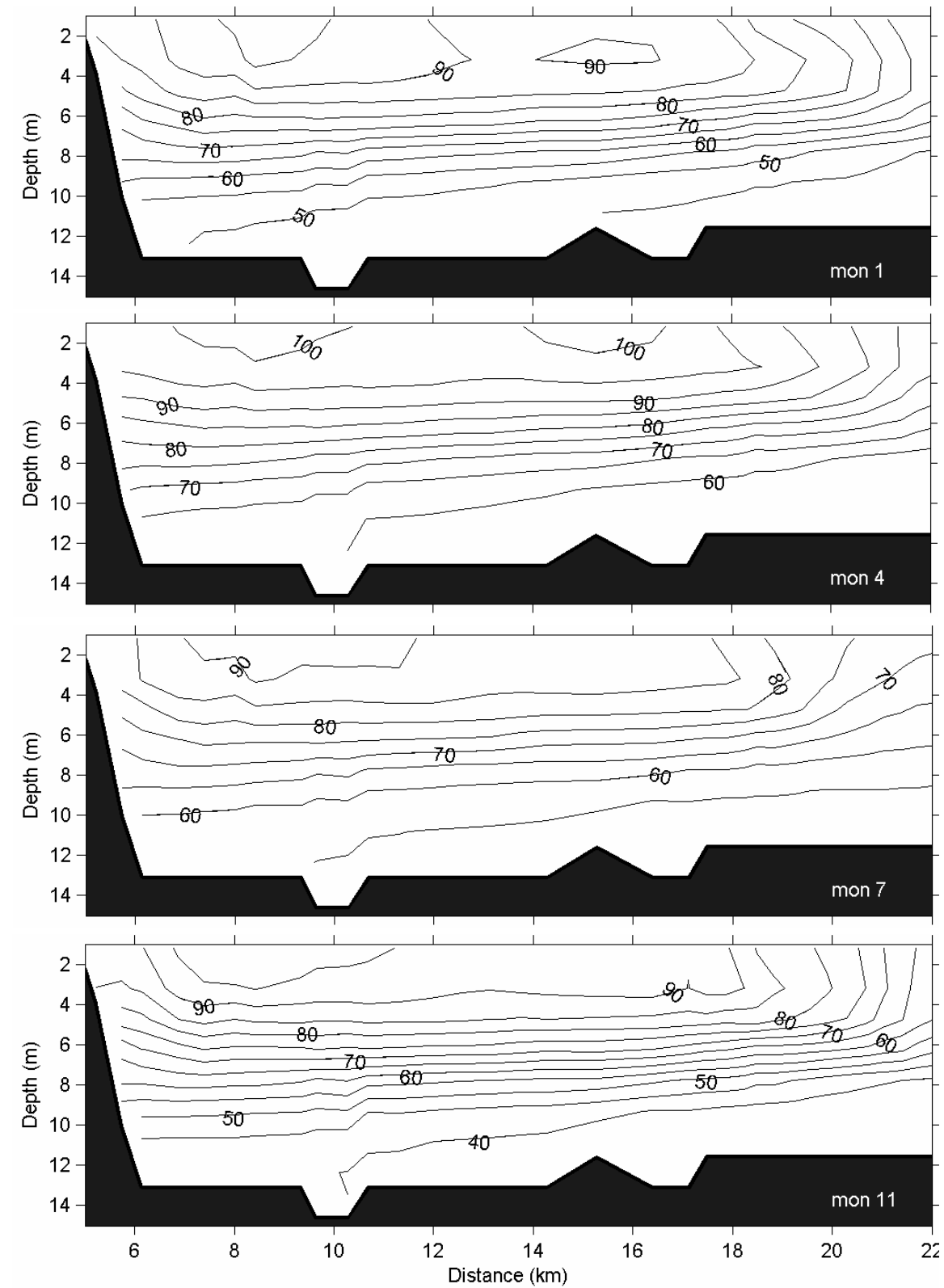

Figure 10. Same as Fig. 8, but for the results of Exp.2. 

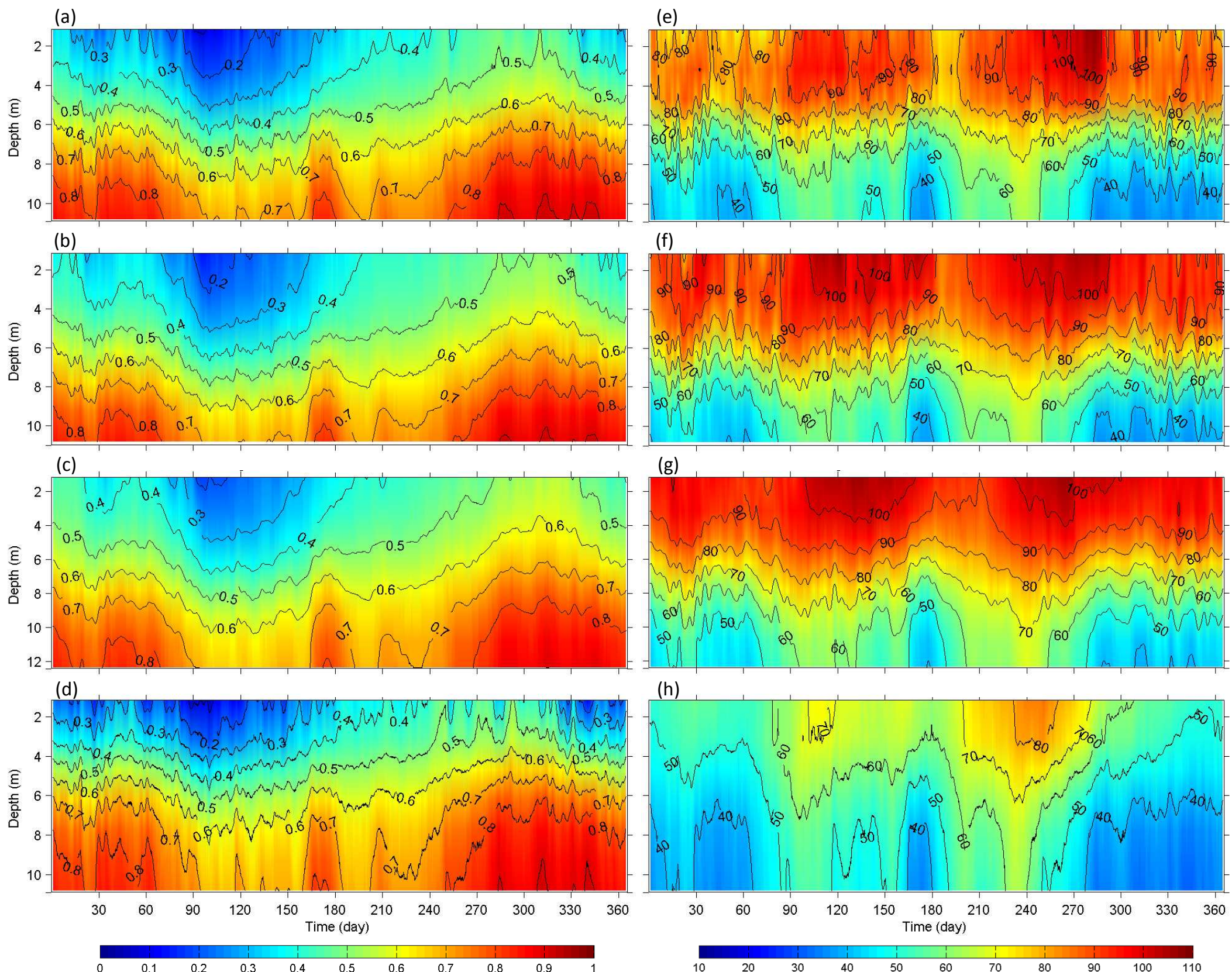

Figure 11. Same as Fig. 9, but for the results of Exp.2. 


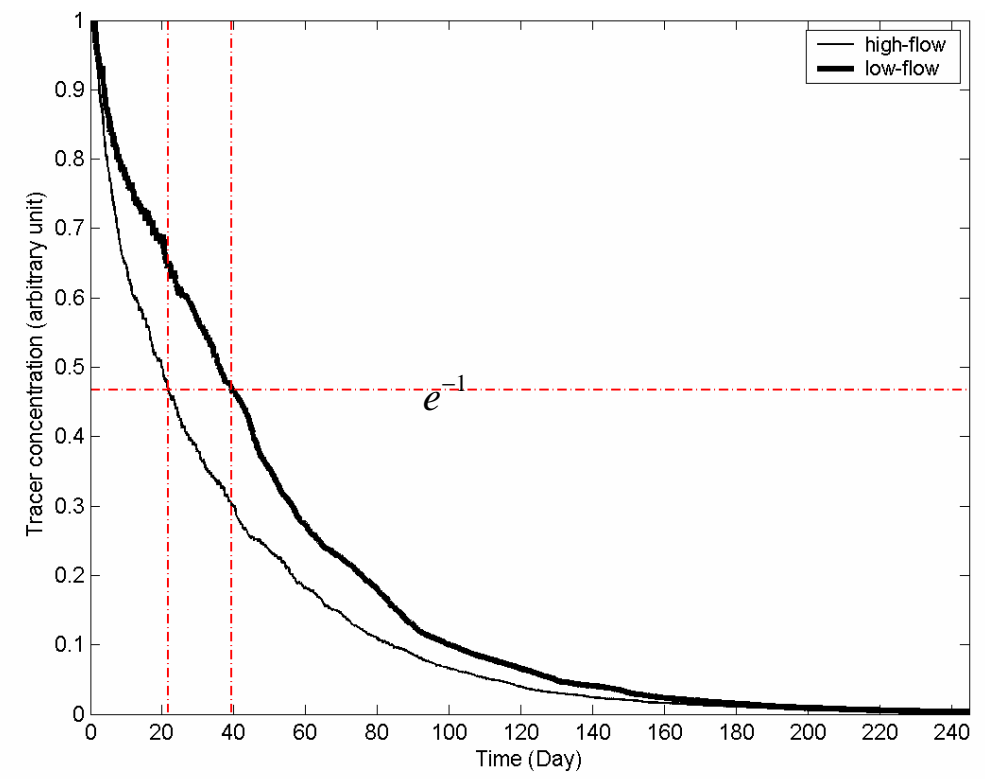

Figure 12. Temporal evolution of total tracer concentrations (arbitrary unit) in Baltimore Harbor under high-flow (thin line) and low-flow (bold line) condition, respectively. The dashed lines indicate where the total tracer concentration is reduced to a factor of $\mathrm{e}^{-1}$ (i.e., measure of the turnover time of the Harbor waters). 

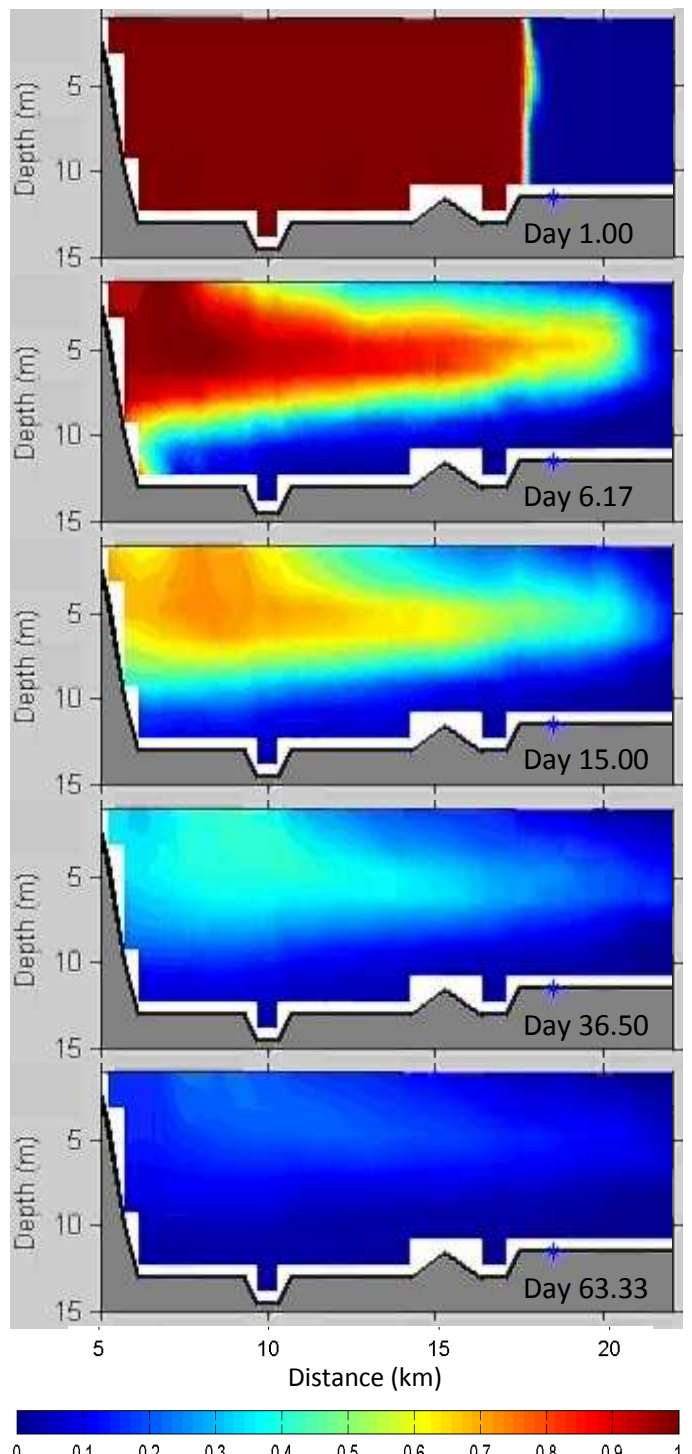

Figure 13. Evolution of tracer concentrations (arbitrary unit) in the case of releasing tracers instantly in Baltimore Harbor under typical wet condition (Exp. 3). Chesapeake Bay lies to the right of the figure. The abscissa is consistent with the model abscissa in Figure 2. 
(a)

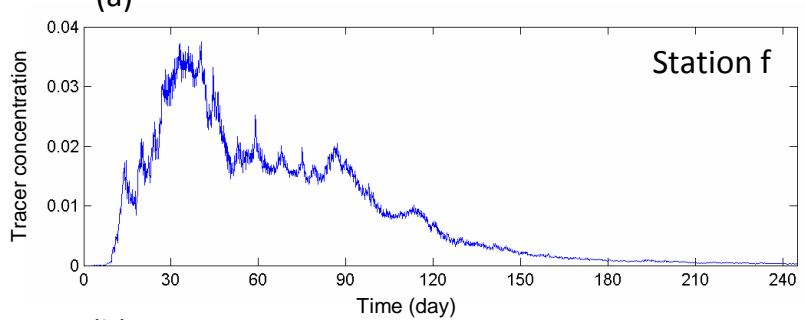

(b)
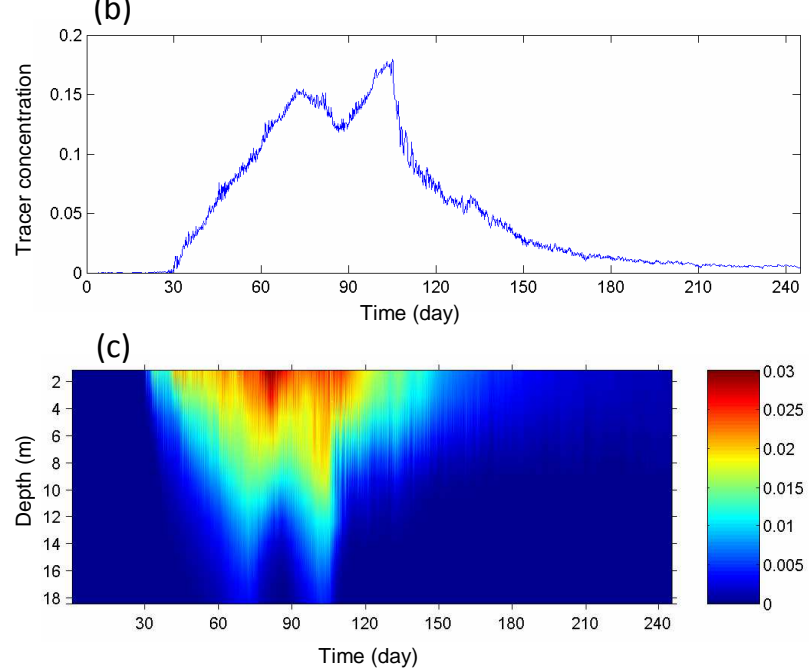
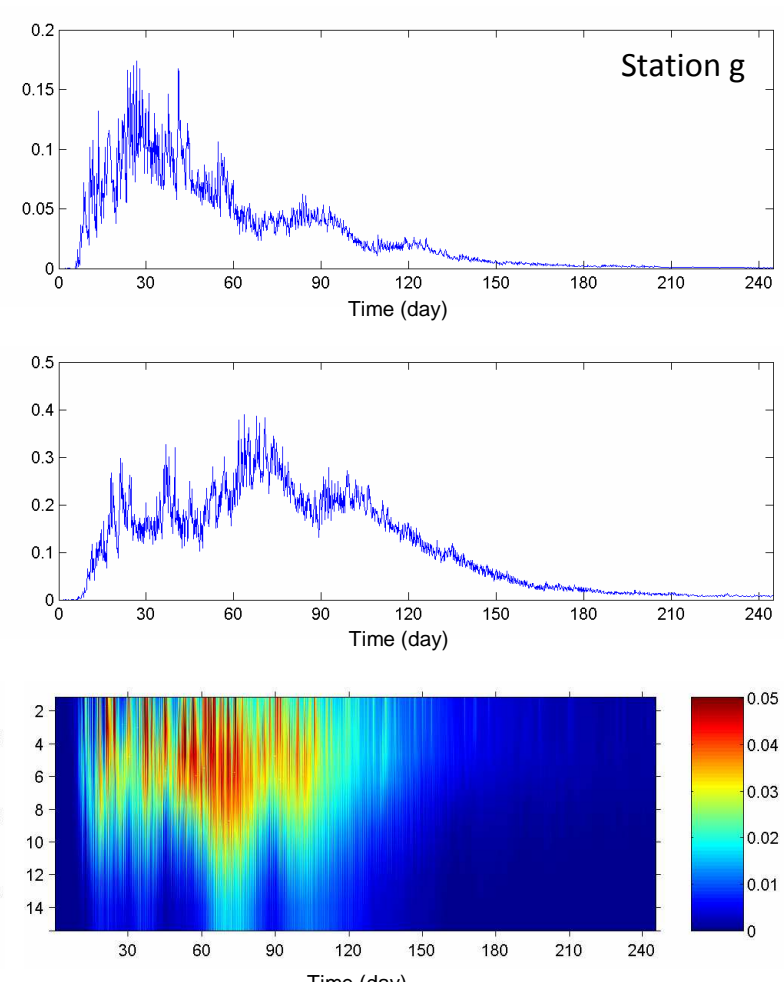

Time (day)
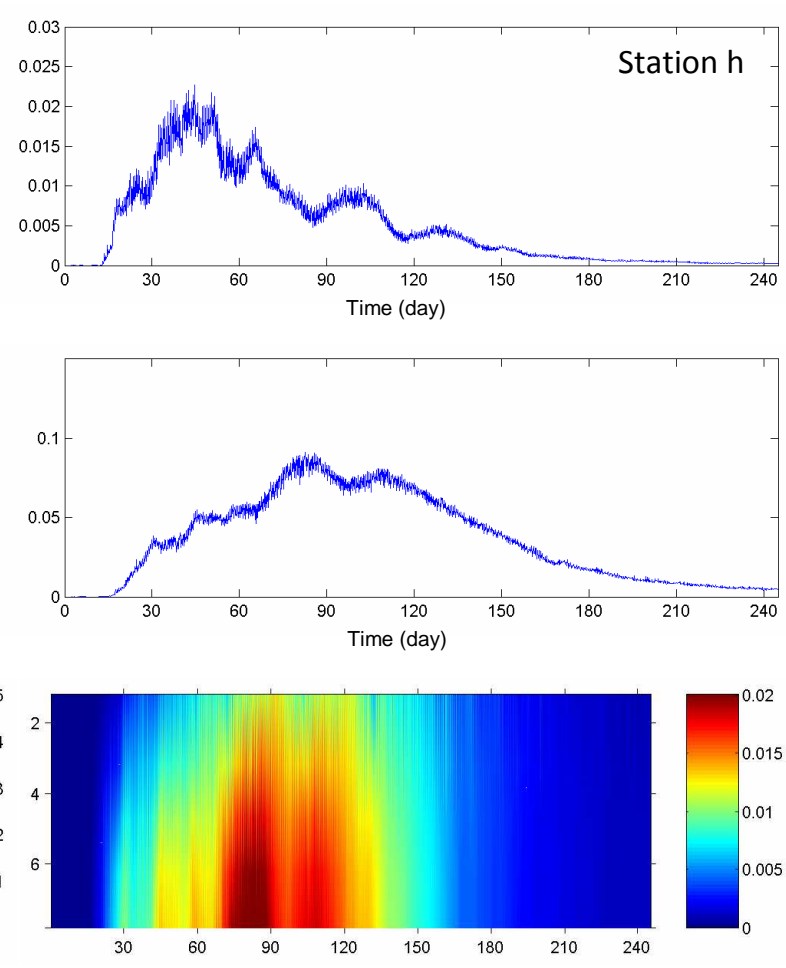

Time (day)

Figure 14. Time series of depth-averaged tracer concentration (arbitrary unit) under (a) typical wet and (b) typical dry conditions. The temporal vertical profiles of tracer concentrations under typical dry condition (the same pattern occurs during the typical wet condition) are shown in (c). In each row, the results at Stations $\mathrm{f}, \mathrm{g}$, and $\mathrm{h}$ are presented from the left to the right. 

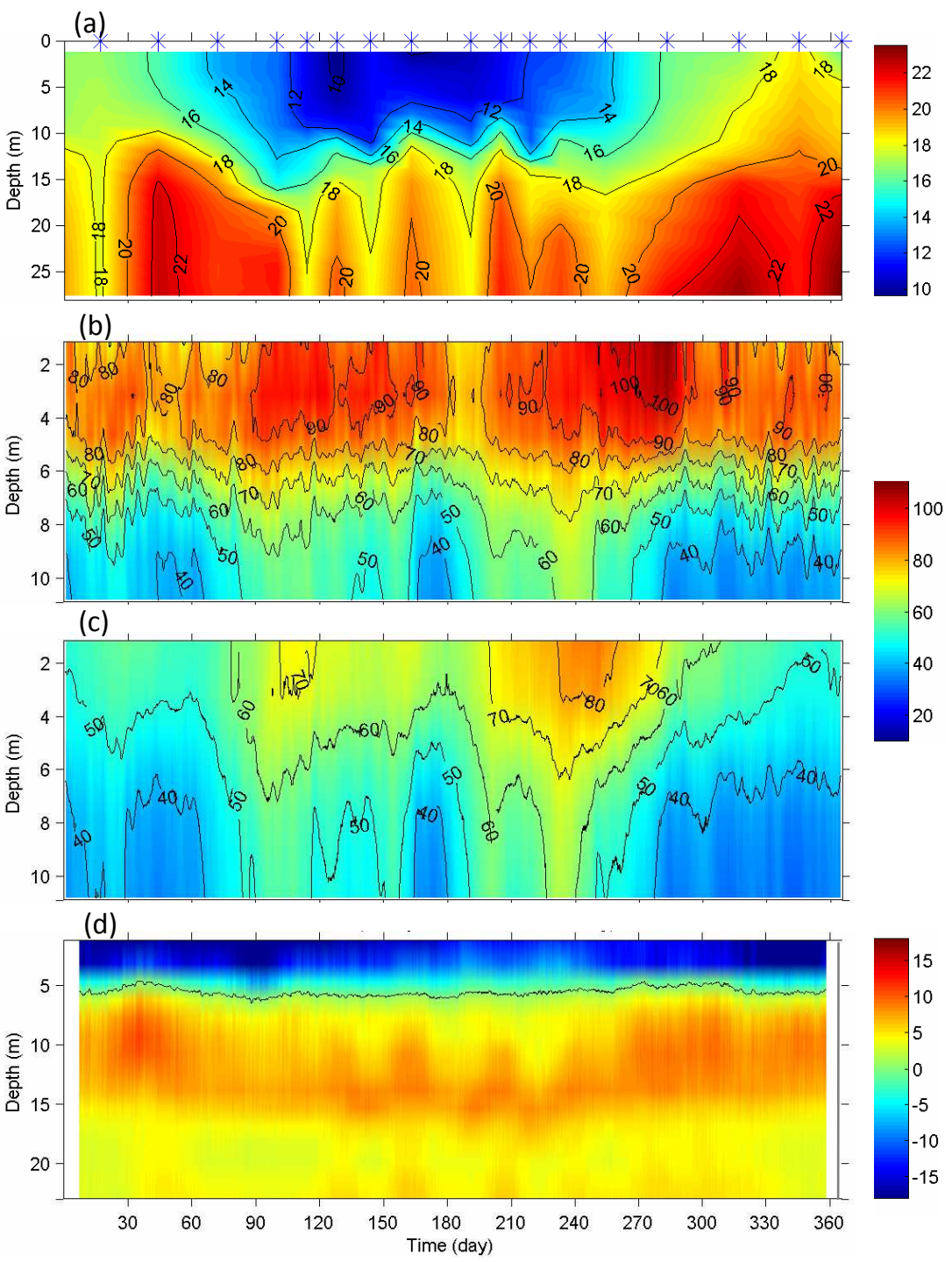

Figure 15. The temporal vertical profile of (a) observed salinity (ppt) at Station CB4.4; (b) water age (day) at Station C (Exp. 2); (c) water age at Station B (Exp. 2); and (d) residual velocity $\left(\mathrm{cm} \mathrm{s}^{-1}\right)$ at Station V. The negative (positive) velocity represents the seaward (landward) flow. 


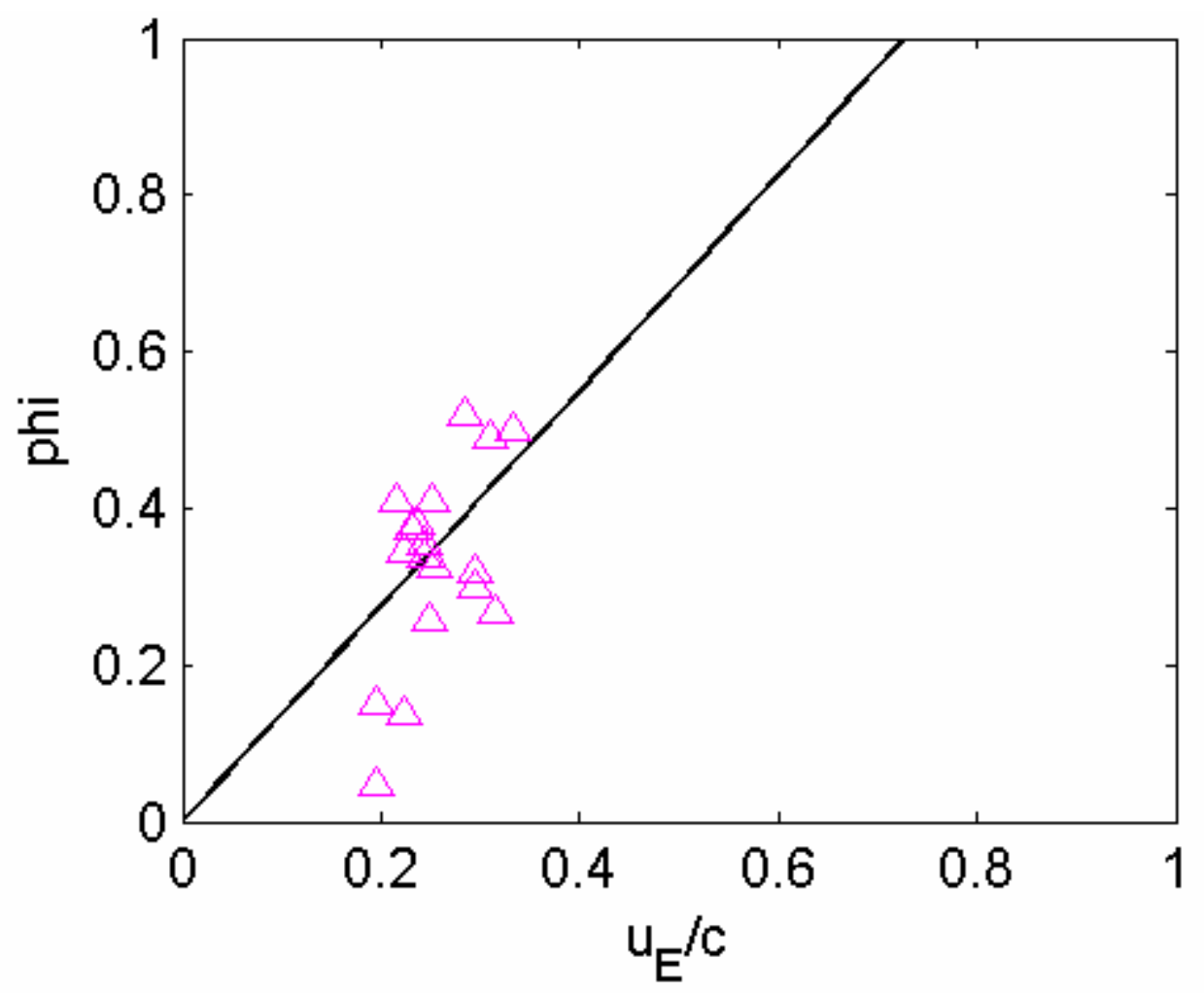

Figure 16. The plane $\left(U_{E} / c, \Phi\right)$ presentation of all possible estuary states. $\Phi$ and $U_{E} / c$ denotes the dimensionless stratification and exchange flow, respectively. The solid line represents the results calculated using theoretical solution, the triangle represents the results calculated using the 3D model. 